\title{
Autophagy links antimicrobial activity with antigen presentation in Langerhans cells
}

\author{
Angeline Tilly Dang, ${ }^{1,2}$ Rosane M.B. Teles, ${ }^{1}$ Phillip T. Liu, ${ }^{1,3}$ Aaron Choi, ${ }^{1,2}$ Annalisa Legaspi, ${ }^{1}$ \\ Euzenir N. Sarno, ${ }^{4}$ Maria T. Ochoa, ${ }^{5}$ Kislay Parvatiyar, ${ }^{2}$ Genhong Cheng, ${ }^{2}$ Michel Gilliet, ${ }^{6}$ \\ Barry R. Bloom, ${ }^{7}$ and Robert L. Modlin ${ }^{1,2}$ \\ 'Division of Dermatology, Department of Medicine, and 'Department of Microbiology, Immunology and Molecular Genetics, \\ David Geffen School of Medicine at University of California, UCLA, Los Angeles, California, USA. ${ }^{3}$ UCLA and Orthopaedic \\ Hospital, Department of Orthopaedic Surgery and the Orthopaedic Hospital Research Center, Los Angeles, California, USA. \\ ${ }^{4}$ Leprosy Laboratory, Oswaldo Cruz Foundation, Rio de Janeiro, Brazil. ${ }^{5}$ Department of Dermatology, University of Southern \\ California School of Medicine, Los Angeles, California, USA. ${ }^{6}$ Department of Medicine, Dermatology Service, Lausanne \\ University Hospital of Lausanne, Lausanne, Switzerland. 'Harvard School of Public Health, Boston, Massachusetts, USA
}

DC, through the uptake, processing, and presentation of antigen, are responsible for activation of $T$ cell responses to defend the host against infection, yet it is not known if they can directly kill invading bacteria. Here, we studied in human leprosy, how Langerhans cells (LC), specialized DC, contribute to host defense against bacterial infection. IFN- $\gamma$ treatment of $L C$ isolated from human epidermis and infected with Mycobacterium leprae ( $M$. leprae) activated an antimicrobial activity, which was dependent on the upregulation of the antimicrobial peptide cathelicidin and induction of autophagy. IFN- $\gamma$ induction of autophagy promoted fusion of phagosomes containing $M$. leprae with lysosomes and the delivery of cathelicidin to the intracellular compartment containing the pathogen. Autophagy enhanced the ability of M. leprae-infected LC to present antigen to CD1a-restricted T cells. The frequency of IFN- $\gamma$ labeling and LC containing both cathelicidin and autophagic vesicles was greater in the self-healing lesions vs. progressive lesions, thus correlating with the effectiveness of host defense against the pathogen. These data indicate that autophagy links the ability of DC to kill and degrade an invading pathogen, ensuring cell survival from the infection while facilitating presentation of microbial antigens to resident $\mathrm{T}$ cells.

Conflict of interest: The authors have declared that no conflict of interest exists.

Copyright: () 2019 American Society for Clinical Investigation

Submitted: December 19, 2018 Accepted: March 7, 2019 Published: April 18, 2019.

Reference information: /CI Insight. 2019;4(8):e126955. https://doi. org/10.1172/ji.insight.126955

\section{Introduction}

Langerhans cells (LC) are members of the DC family of professional antigen presenting cells that are distinguished by their residence in the epidermis of skin and mucosa, high expression of CD1a (1), and unique expression of langerin (CD207). As part of the host innate immune system at the interface with the external environment, LC are equipped with endocytic receptors for phagocytosis $(2,3)$ and have a key role in antigen presentation to T cells (4). In response to cutaneous fungal infection, LC are required for $\mathrm{T}$ cell differentiation (5-7).

CD1a is part of the human cluster of differentiation 1 (CD1) gene family consisting of a small number of genes that are structurally related to the MHC class I genes (8); however, unlike MHC class I molecules, CD1 proteins are nonpolymorphic. The CD1a, -b, and -c molecules are more closely homologous to one another than to CD1d (8) and are absent in mice. In skin, CD1a and -c isoforms are present on the surface of LC; whereas, CD1a, -b, and -c are expressed on dermal DC (9-11). CD1a-restricted $\mathrm{T}$ cell responses include autoreactive $(12,13)$ as well as against mycobacterial antigens, including host-derived sulfatides (14), "headless antigens" (13), pollen phospholipids (15), and dideoxymycobactin (16). The crystal structure of CD1a has been resolved with both sulfatide (17) and dideoxymycobactin (18), indicating the presence of 2 hydrophobic binding pockets $\mathrm{A}^{\prime}$ and $\mathrm{F}^{\prime}$. CD1a autoreactive T cells home to skin (19), recognizing CD1a loaded with skin-derived lipids (13), including - as we showed - lipids processed into free fatty acids (20), which allow direct interaction between the $\mathrm{T}$ cell receptor and CD1a (21). 
Leprosy, an infection of skin caused by the intracellular pathogen Mycobacterium leprae ( $M$. leprae), provides a model to study mechanisms of host defense against an intracellular bacterial pathogen at the site of infection. The disease presents as a spectrum, in which the clinical manifestations correlate with the ability of the immune response to contain the pathogen. There are increased numbers of $\mathrm{CD} 1 \mathrm{a}^{+} \mathrm{LC}$, both in the epidermis and dermal granulomas of the skin lesions-from the self-limiting tuberculoid (T-lep) form vs. the progressive lepromatous (L-lep) form of leprosy $(9,22,23)$. LC have been shown to present $M$. leprae antigens to T cell clones derived from skin lesions of T-lep patients in a CD1a-restricted manner (24). Of relevance, the earliest lesions of leprosy are thought to arise in the epidermis (25), and LC have been shown to be infected by M. leprae (26).

There are several mechanisms by which CD1-restricted $\mathrm{T}$ cells contribute to host defense against mycobacterial infection (27-30). Some mycobacteria-specific group I CD1-restricted T cells secrete the Th1 pattern of cytokines (27), are cytolytic against infected targets $(27,31)$, and trigger antimicrobial activity (29, 32). These antimicrobial $\mathrm{T}$ cells express perforin, granzyme $\mathrm{B}$, and the antimicrobial protein granulysin in intracellular granules (29). Furthermore, the ability of these T cells to release IFN- $\gamma$ potentially leads to induction of autophagy as well as the vitamin D-dependent antimicrobial response in monocytes and macrophages, including upregulation of the antimicrobial peptides CAMP and DEFB4 (encoding cathelicidin [Cath]/LL-37 and human $\beta$-defensin-2, respectively) (33-35). Autophagy is an evolutionarily conserved process in which eukaryotic cells break down cytoplasmic contents by usage of the lysosomes during times of low nutrients or starvation, often as a result of an infection $(36,37)$. While it has been reported that suppression of Cath during $M$. tuberculosis infection resulted in reduced levels of autophagy in macrophages (38), the role of Cath is still unclear in DC (39).

Although LC have been shown to mediate an antiviral activity (40-42), there is little evidence that LC contribute to antibacterial immunity, rather the opposite that LC contribute to progressive infection (3). Yet in order to fulfill their function as antigen presenting cells, it is reasonable to expect that DC such as LC can mount an antibacterial response in order to facilitate processing of microbial antigens for presentation to $\mathrm{T}$ cells during active infection. Therefore, this work was undertaken to learn, through the study of leprosy, whether LC were capable of exerting an antimicrobial response with the ability to process bacterial-derived antigen for presentation to $\mathrm{T}$ cells.

\section{Results}

$I F N-\gamma$ induced antimicrobial activity in LCDC and epidermal LC. Given the increased numbers of LC in the epidermis of T-lep vs. L-lep patients $(9,22,23)$, we sought to determine whether LC could encounter IFN- $\gamma$ in this location. Previously, IFN- $\gamma$ mRNA was found to be more highly expressed in T-lep vs. L-lep lesions (43-45), yet it was unclear if IFN- $\gamma$ protein was present in the epidermis in these lesions. Here, we detected higher levels of IFN- $\gamma$ protein by immunoperoxidase and immunofluorescence in the epidermis of T-lep vs. L-lep lesions, colocalizing with CD1a ${ }^{+}$LC (Figure 1, A-C, and Supplemental Figure 1; supplemental material available online with this article; https://doi.org/10.1172/jci.insight.126955DS1).

IFN- $\gamma$ is known to activate antimicrobial pathways to kill intracellular pathogens. We sought determine whether this cytokine could induce an antimicrobial activity in M. leprae-infected LC. LC-like DC (LCDC) were derived from $\mathrm{CD} 34^{+}$hematopoietic precursor cells, which have been used as surrogates for LC (Supplemental Figure 2A) $(24,41,46)$. Electron microscopy of LCDC confirmed the presence of Birbeck granules, which are specific for LC (Supplemental Figure 2B). In addition, epidermal CD $1 \mathrm{a}^{+} \mathrm{LC}$ were also isolated from healthy skin (Supplemental Figure 2C) $(6,47)$. To establish whether M. leprae is able to infect LC in vitro, as this has not been demonstrated, LCDC and epidermal LC were cultured with live $M$. leprae at increasing multiplicities of infection (MOI) of 5, 10, and 20 per cell. A MOI of 10 yielded approximately $50 \%$ of the cells infected with $M$. leprae, with approximately 3-5 bacilli per cell. Both LCDC and LC maintained cellular morphology (Supplemental Figure 3, A and B) and retained the expression of the LC-specific marker CD207/langerin (Supplemental Figure 3C).

To measure the antimicrobial response of LC against intracellular $M$. leprae, bacterial viability was measured according to the ratio of bacterial 16S rRNA to repetitive element DNA using a PCR-based method $(45,48,49)$, as the bacteria cannot be grown in culture. LCDC were infected with $M$. leprae, cultured with $10 \%$ human vitamin D-sufficient serum, and stimulated with either IFN- $\gamma$ or media control. IFN- $\gamma$ treatment of infected LCDC resulted in the induction of significant antimicrobial activity vs. media control $(83 \% \pm 5 \%$, $P<0.001$; Figure 1D). Similarly, IFN- $\gamma$-treated CD1a ${ }^{+}$epidermal LC induced a significant antimicrobial response against $M$. leprae $(77 \% \pm 4 \%, P<0.001$; Figure $1 \mathrm{E})$. Conversely, IFN- $\gamma$ treatment of the CD1a ${ }^{-}$epi- 
dermal cells, which contained $<10 \%$ LC, induced an approximately 6-fold lower antimicrobial response $(12 \%$ $\pm 2 \%, P<0.03$ of $\mathrm{CD}_{1 \mathrm{a}}{ }^{+}$vs. CD1-negative LC; Figure $\left.1 \mathrm{~F}\right)$, suggesting that the CD1a $\mathrm{aC}^{+}$mount a more robust antimicrobial response. As a control, we treated $M$. leprae-infected LCDC with IL-4, a cytokine more highly expressed in L-lep lesions. This did not induce an antimicrobial response (Supplemental Figure 4).

$I F N-\gamma$ induces autophagy and phagolysosomal fusion in $M$. leprae-infected $L C$. The ability of $M$. leprae to block phagolysosomal fusion in macrophages prevents the delivery of antimicrobial effector molecules from lysosomes into the phagosomes, which contain the invading bacteria (50-55). This blockade can be overcome by the cellular process of autophagy, through the creation of autophagosomes and their subsequent fusion with lysosomes $(34,35,56-60)$. Because there is little information on the induction of autophagy and its biological role in LC, we stimulated LCDC and epidermal LC with IFN- $\gamma$ and the induction of autophagy was assessed by LC3 aggregation. IFN- $\gamma$ induced an increase LC3 aggregation in both LCDC and epidermal CD1a ${ }^{+}$LC as compared with cells cultured with media control (Figure 2, A-D). LCDC had $18.6 \pm 2$ puncta per cell for IFN- $\gamma$ treatment vs. $0.9 \pm 0.3 \mathrm{LC} 3$ puncta per cell for media treatment $(P<0.01$; Figure $2 \mathrm{~B})$. Similarly, epidermal LC expressed $22.0 \pm 1.9$ puncta per cell for IFN- $\gamma$ treatment as compared with $2.5 \pm 0.7$ LC3 puncta per cell for media treatment $(P<0.01$; Figure 2D). The ability of IFN- $\gamma$ to induce autophagy was also evidenced by an increase in the percentage of cells with $\mathrm{LC}^{+}$vesicles (Supplemental Figure 5, A and B), as well as the accumulation of LC3-II protein resulting from the cleavage of LC3-I precursor (Supplemental Figure 5C) (61). We also utilized acridine orange, a lysosomotropic dye, to quantify the IFN- $\gamma$-induced formation of acidic vesicular organelles (AVO) (Supplemental Figure 6A) $(62,63)$. Analogous to the number of LC3 puncta, IFN- $\gamma$ induced more AVO puncta per cell than media treated LCDC, 19.0 \pm 0.9 vs. 5.21.0 AVO per cell $(P<0.01$; Supplemental Figure 6B). Electron micrograph revealed that IFN- $\gamma$ stimulation of LCDC induced a significant increase in the number of electron-dense endolysosomes compared with media control: $22.1 \pm$ 1.2 vs. $7.7 \pm 0.7$ endolysosomes per cell $(P<0.01$; Supplemental Figure $6, C$ and $D)$. Utilizing the principles of point counting (64), we quantified the cellular volume of single-membrane and double-membrane compartments, the latter being a characteristic of autophagosomes. LCDC treated with IFN- $\gamma$ had higher double-membrane volume than media control, $0.07 \pm 0.01 \mu \mathrm{m}^{3}$ vs. $0.02 \pm 0.01 \mu \mathrm{m}^{3}(P<0.03)$, while the inverse was observed between the conditions with single-membrane volume (Supplemental Figure $6 \mathrm{E}$ ).

We next investigated the effects IFN- $\gamma$-mediated phagosome maturation and phagolysosomal fusion during M. leprae infection. As compared with cells treated with media alone, IFN- $\gamma$ treatment of M. lepraeinfected LCDC induced autophagy as well as colocalization of intracellular bacteria to the autophagosome, identified by LC3 aggregation and colocalization with the labeled $M$. leprae bacilli and further delineated by 3-dimensional modeling (Figure $2 \mathrm{E}$ ). IFN- $\gamma$ treatment of LCDC also resulted in colocalization of bacilli and LAMP1, a lysosome marker, indicating that the majority of $M$. leprae bacilli were localized to the lysosome compartment (Figure 2F). Furthermore, IFN- $\gamma$ stimulation of $M$. leprae-infected LCDC triggered autophagolysosomal fusion, as evidenced by the colocalization of the bacilli with LC3 and LAMP1 (Figure $2 \mathrm{G})$. By electron microscopy (EM), we confirmed that, in IFN- $\gamma$-treated LCDC, the $M$. leprae bacilli were contained within compartments surrounded by autophagosomes, characterized by double-membrane vesicles. We also detected evidence by EM of IFN- $\gamma$-induced fusion between autophagosomes, characterized by double membranes and containing bacilli, with lysosomes. In contrast, the majority of the intracellular bacilli in the control LCDC treated with media were contained in phagosomes with a single membrane $(>90 \%$; Figure $2 \mathrm{H}$ and Supplemental Figure $6 \mathrm{~F}$ ). Additionally, the mycobacterial cell walls were mostly intact in the media control-treated LCDC, while in IFN- $\gamma$-treated LCDC, the cells walls were often degraded and the bacilli lysed. Together, these data demonstrate that $M$. leprae blocks the inhibition of autophagolysosomal fusion is overcome by IFN- $\gamma$ activation, facilitating an antimicrobial response.

IFN- $\gamma$ induces antimicrobial peptides in $L C$. IFN- $\gamma$ can trigger an antimicrobial response against intracellular pathogens by a variety of mechanisms, including the vitamin $\mathrm{D}$-dependent generation of antimicrobial peptides CAMP and DEFB4 in monocytes and macrophages $(33,34)$. The addition of IFN- $\gamma$ was determined to be sufficient to induce the gene expression of the antimicrobial peptides CAMP and DEFB4 in both LCDC (Figure 3A) and epidermal CD1a+ LC (Figure 3B). IFN- $\gamma$ was also sufficient to induce Cath protein in LCDC as detected by confocal laser microscopy (Figure 3C and Supplemental Figure 7A). The percentage of Cath ${ }^{+}$ cells was significantly greater in IFN- $\gamma$ vs. media-treated LCDC ( $74 \% \pm 2 \%$ vs. $4.9 \% \pm 2.7 \%$ in media control, $P<0.002$, Figure 3D). In contrast, $\beta$-defensin- 2 protein expression was detected in CD $1 \mathrm{a}^{+} \mathrm{LCDC}$ treated with media and was not further induced by IFN- $\gamma$ stimulation, suggesting that it is constitutively expressed (Supplemental Figure 7, B and C), consistent with its constitutive expression in the skin (65). 
$\mathbf{A}$
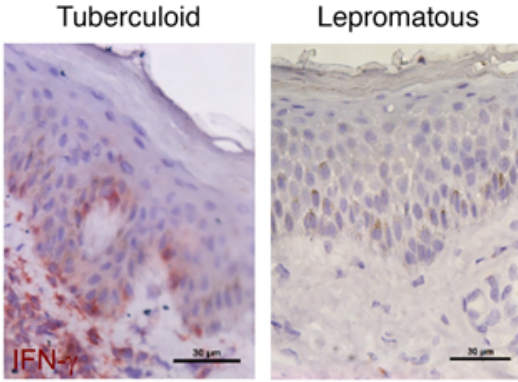

C

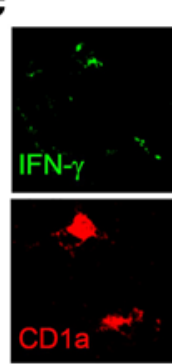

Tuberculoid

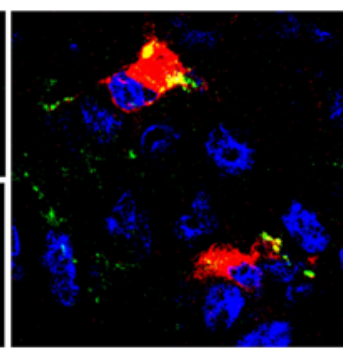

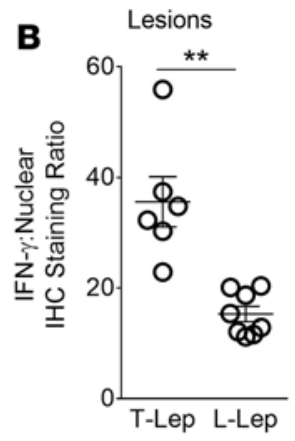

Lepromatous
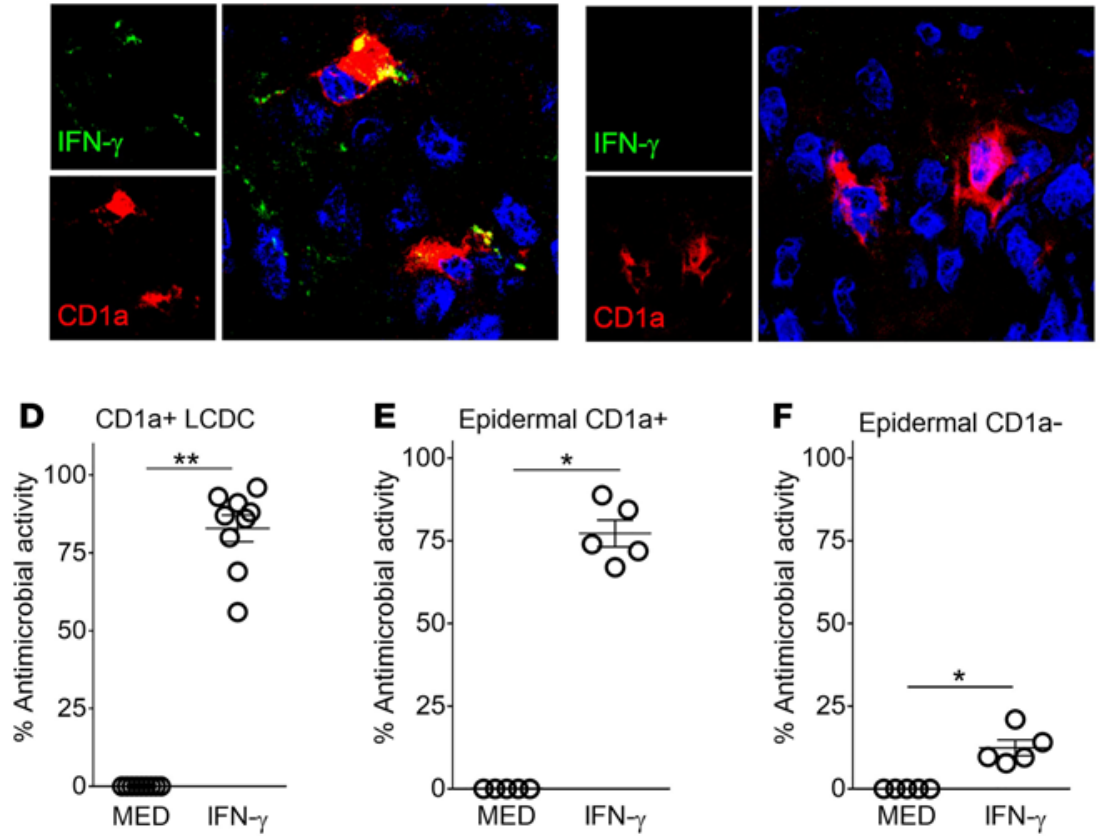

Figure 1. IFN- $\gamma$ induces antimicrobial activity in Langerhans cells. (A) IFN- $\gamma$ expression in leprosy lesions, tuberculoid (T-lep), and lepromatous (L-lep); 1 representative labeled section is shown out of 4 individuals at 20x. Scale bar: 30 $\mu \mathrm{m}$. (B) Ratio of IFN- $\gamma$ and nuclear staining quantified by ImmunoRatio. Data are represented as mean \pm SEM, $n=6$ IHC sections. (C) Colocalization of IFN- $\gamma$ (green) and CD1a (red) in T-lep lesions. Data are representative of 3 individual T-lep or L-lep lesions at 63x. (D) Human LCDC were stimulated with recombinant IFN- $\gamma$ for 4 hours, washed and infected with $\mathrm{M}$. leprae at a $\mathrm{MOI}$ of 10 overnight, and washed and stimulated with rIFN- $\gamma$ for an additional 4 days. Viability of $M$. leprae was calculated by the ratio of bacterial 16S RNA and DNA (RLEP) detected by qPCR, and percent increase or decrease relative to no treatment (media) was determined. Data are represented as mean $\pm \mathrm{SEM}, n=9$. (E) Human primary CD1a+ epidermal cells or (F) CD1a-e epidermal cells were stimulated with rIFN- $\gamma$ for 4 hours and washed and infected with $M$. leprae as in $\mathbf{D}$. Viability of $M$. leprae was calculated as described in $\mathbf{D}$. Data are represented as mean \pm SEM, $n=5 .{ }^{*} P<0.05,{ }^{* *} P<0.01$. Two-tailed Student's $t$ test.

IFN- $\gamma$ induction of Cath in infected LCDC resulted in the colocalization of Cath with intracellular M. leprae. In IFN- $\gamma$-treated LCDC, Cath was detected surrounding intracellular bacilli and localized to the LAMP1+ lysosome (Figure 3E). In contrast, media treatment of LCDC did not result in detectable Cath. Therefore, to determine the role of Cath in LC-mediated antimicrobial activity against M. leprae, transfection of siRNAs targeting Cath mRNA was used. Approximately 50\% specific knockdown of Cath mRNA was achieved, affecting cell viability by $<10 \%$ (Supplemental Figure 8 A). Vitamin D receptor (VDR) mRNA levels were unaffected by siRNA targeting Cath (Supplemental Figure 8B). In these experiments, the knockdown of Cath reduced IFN- $\gamma$-induced antimicrobial activity from $77 \% \pm 2 \%$ to $29 \% \pm 5 \%(P<0.02)$, an approximately $60 \%$ reduction compared with IFN- $\gamma$ paired with the small interfering control (siCTRL) (Figure 3F). During M. leprae infection, Cath peptide was undetectable in media control-treated LCDC but was found to colocalize with $M$. leprae inside LAMP1+ vesicles when stim- 
$\mathbf{A}$

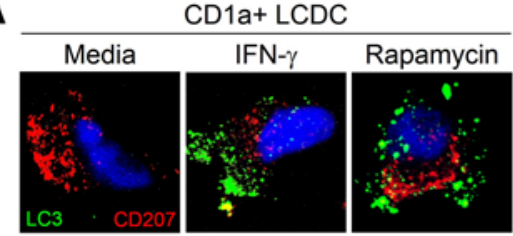

C

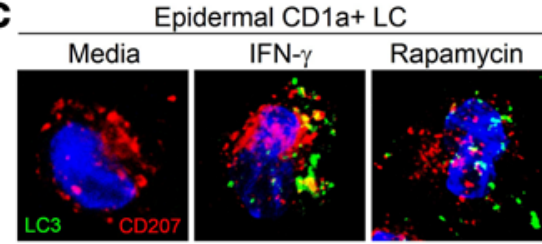

E

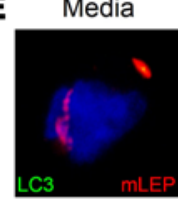

F
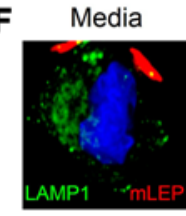

G

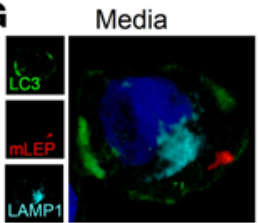

IFN- $\gamma$

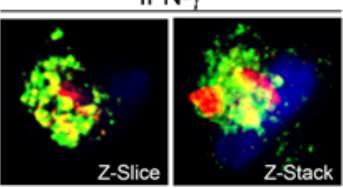

IFN- $\gamma$

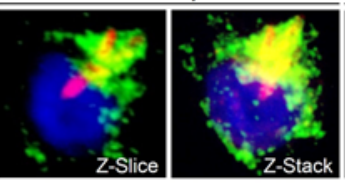

IFN- $\gamma$

\section{B $\quad \mathrm{CD} 1 \mathrm{a}+\mathrm{LCDC}$}

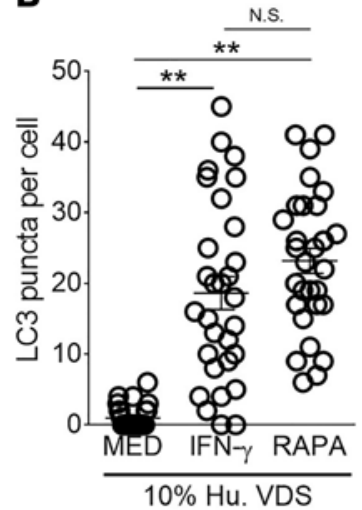

Epidermal CD1a+

IFN- $\gamma$ : 3D Model

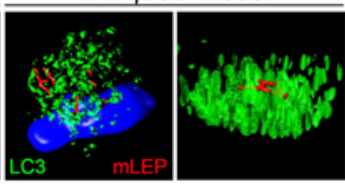

IFN- $\gamma$ : 3D Model
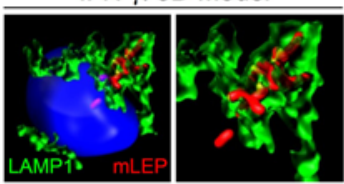

IFN- $\gamma: 3 D$ Model

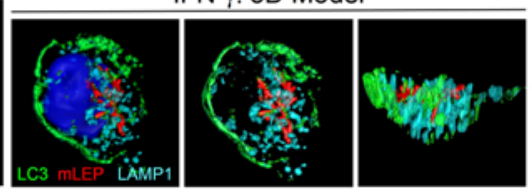

IFN- $\gamma$
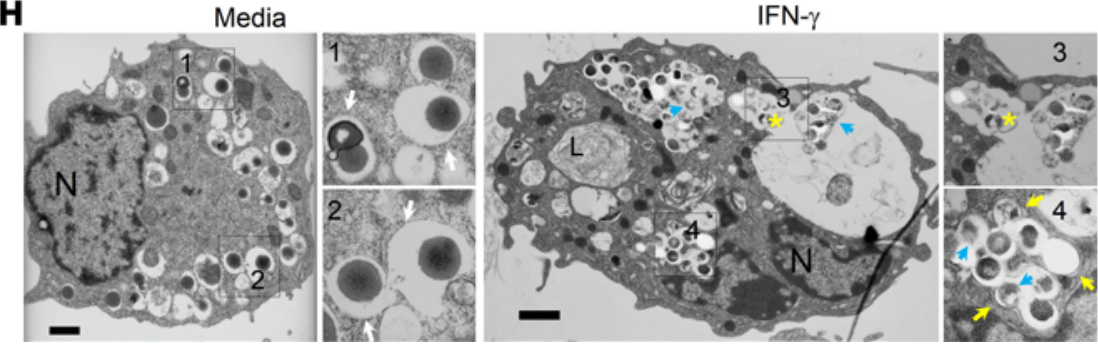

Figure 2. IFN- $\gamma$ induces autophagy in Langerhans cells. (A) Human LCDC were cultured with rIFN- $\gamma$, rapamycin, or medium overnight in $10 \%$ vitamin D-sufficient human serum, and they were fixed and immunolabeled with anti-LC3 antibody (green) and anti-CD207/langerin antibody (red). Nuclei were stained with DAPI (blue). Representative shown of 4 independent experiments. (B) The number of LC3 puncta per cell were quantified. Data are represented as mean puncta per cell \pm SEM, $n \geq 30$ cells. (C) Human primary CD1a+ LC were cultured and labeled as in $\mathbf{A}$. Representative immunofluorescence images of 3 independent experiments are shown. (D) The number of LC3 puncta per cell were quantified. Data are represented as mean puncta per cell \pm SEM, $n \geq 25$ cells. (E-H) Human LCDC were stimulated with rIFN- $\gamma$ for 4 hours, washed and infected with PKH26-M. leprae (red) at a MOI of 10 overnight, and washed and stimulated with rIFN- $\gamma$ for an additional 4 hours. (E) Infected cells were fixed and immunolabeled with anti-LC3 antibody (green). Representative shown of 4 independent experiments. (F) Infected cells were fixed and immunolabeled with anti-LAMP1 antibody (green). Representative shown of 4 independent experiments. (C) Infected cells were fixed and immunolabeled with anti-LC3 antibody (green) and anti-LAMP1 antibody (cyan). Representative shown of 3 independent experiments. (A, C, F, and G) Images captured on a $63 \times$ lens, with $6 \times$ zoom. (H) Infected cells were fixed and processed for electron microscopy. N, nucleus; L, lysosome. Black boxes labeled 1-4 correspond with magnifications shown. White arrows indicate single-membrane phagosomes. Yellow arrows indicate double-membrane autophagosomes. Blue arrows indicate digested bacteria. Yellow asterisks indicate fusion of autophagosome with lysosome. Scale bars: $1 \mu \mathrm{m}$. Representative images of 3 independent experiments are shown. ${ }^{* *} P<0.01$. Repeated measures 1-way ANOVA. 
ulated with IFN- $\gamma$ (Figure 3, E and G). Correspondingly, the transfection of siRNA oligos specific for Cath (siCath) prior to IFN- $\gamma$ stimulation of LCDC ablated Cath detection at both the protein and mRNA levels (Figure 3G and Supplemental Figure 8C). These data indicate that IFN- $\gamma$-induced antimicrobial activity in LC is dependent on the induction of Cath.

Characterization of $L C$ in leprosy lesions. To investigate whether IFN- $\gamma$ induction of autophagy and Cath in LC was relevant at the site of infection in leprosy, we utilized confocal microscopy. LC3 puncta were detected in $\mathrm{CD}_{1 \mathrm{a}}{ }^{+} \mathrm{LC}$ in T-lep but not L-lep lesions, indicating the presence of autophagic responses (Figure 4, A and B, and Supplemental Figure 9, A and B). Cath protein was ubiquitously expressed in the epidermis of T-lep lesions and colocalized with CD1a+ LC. In contrast, in L-lep lesions, the expression of Cath was reduced (Figure 4, C-E, and Supplemental Figure 9, C and D). The isotype controls matching all monoclonal antibodies used for labeling were consistently negative (Supplemental Figure 9). Even though the confocal imaging demonstrated colocalization of Cath with CD1a $\mathrm{aC}^{+}$in T-lep lesions, we cannot distinguish if the colocalization is due to cellular production or uptake from extracellular sources, given that Cath is known to be secreted (66). These data corroborate that skin-resident CD1a $\mathrm{a}^{+} \mathrm{LC}$ are in proximity to IFN- $\gamma$ (Figure 1, A and B) and colocalize with Cath and autophagosomes, indicating the presence of key components of this antimicrobial pathway in LC at the site of infection.

As part of the DC family of professional antigen presenting cells, LC are characterized by an enhanced ability to activate $\mathrm{T}$ cell responses. In skin, there is a resident $\mathrm{T}$ cell population that responds to microbial antigens $(67,68)$. To study the resident $\mathrm{T}$ cell response against $M$. leprae, a CD1a-restricted $\mathrm{T}$ cell line, LCD4.G - derived from a T-lep skin lesion - was studied. LCD4.G is CD4 ${ }^{+}$, expressing CD69 and CD45RO but not CD103 or CD45RA, consistent with the T-resident memory $\left(\mathrm{T}_{\mathrm{RM}}\right)$ phenotype (Supplemental Figure 10). Mycobacteria are known producers of a variety of lipids, which can form stable complexes with CD1 molecules and stimulate $\mathrm{T}$ cells $(69,70)$. To validate whether antigen presentation to LCD4.G T cells is CD1a dependent, we added CD1a blocking antibody to LCDC prior to the coculture with T cells. Anti-CD1a blocked the T cell response by about $80 \%$, as compared with the addition of isotype control (Figure 5A). Supernatants, collected from LCD4.G after activation using anti-CD3/CD28 antibodies, contained high levels of IFN- $\gamma$ (Figure 5B). When added to LCDC, the LCD4.G supernatants induced Cath and DEFB4 mRNAs. Neutralization of IFN- $\gamma$ by neutralizing mAbs significantly blocked the induction of Cath and DEFB4 mRNA levels as compared with the isotype control (Figure 5C and Supplemental Figure 11A). Therefore, $\mathrm{T}_{\mathrm{RM}}$ cells, via the secretion of IFN- $\gamma$, triggered the induction of antimicrobial peptides in LCDC. We also determined that the CD1a-restricted T cell clone LCD4.G triggered the IFN- $\gamma$ dependent upregulation of CYP27b1, VDR and CYP24A1 in LCDC (Supplemental Figure 11, B-D), components of the vitamin D antimicrobial pathway.

In studying the role of vitamin D in the LC response, we observed that the ability of IFN- $\gamma$ to induce autophagy was significantly greater in the presence of vitamin D-sufficient sera or the addition of 1,25-dihydroxyvitamin D3 $(1,25 \mathrm{D} 3)$ to vitamin D-insufficient sera (Supplemental Figure 12, A-C). IFN- $\gamma$ induction of Cath, DEFB4, and CYP24A1 mRNAs was dependent on activation of the VDR in both primary epidermal LC (Supplemental Figure 13A) and LCDC (Supplemental Figure 13C). The addition of VDR antagonist ZK 159222 (VAZ) significantly inhibited the induction of these vitamin D-dependent genes. The induction of Cath also required the presence of adequate levels of 25 -hydroxyvitamin D (25D), as treatment of IFN- $\gamma$ in $10 \%$ FCS, which had low 25D concentrations and was unable to induce gene expression (Supplemental Figure $14 \mathrm{~A}$ ) but could be rescued with the addition of 25D or bioactive 1,25D3 (Supplemental Figure 14C). The levels of vitamin D did not affect IFN- $\gamma$ induction of the vitamin D-independent gene CD64 (Supplemental Figure 13, B and D, and Supplemental Figure 14B). Conversely, the IFN- $\gamma$-induced antimicrobial response was vitamin $\mathrm{D}$ dependent, such that even in 25D-insufficient sera, the antimicrobial activity could be restored by in vitro supplementation with $25 \mathrm{D}$ (Supplemental Figure 15, A and B). The data indicate that IFN- $\gamma$ induction of an antimicrobial response in LC is dependent on 25D levels.

Role of autophagy in LC function. In human macrophages, autophagy can be triggered by a vitamin D-dependent pathway $(34,71,72)$, contributing to an antimicrobial response. In contrast, in DC, autophagy is recognized to contribute to effective antigen presentation to $\mathrm{T}$ cells by delivering antigen into antigen processing compartments $(73,74)$. This led us to hypothesize that autophagy may be a conserved mechanism by which DC, such as LC, link antimicrobial activity to efficient presentation of microbial antigens to T cells. To investigate the role of autophagy in LC function, we used the phosphatidylinositol 3-kinase (PI3K) inhibitor wortmannin to block IFN- $\gamma$-induced autophagy (Figure 6A). The addition of wortmannin prior to IFN- $\gamma$ stimulation significantly 

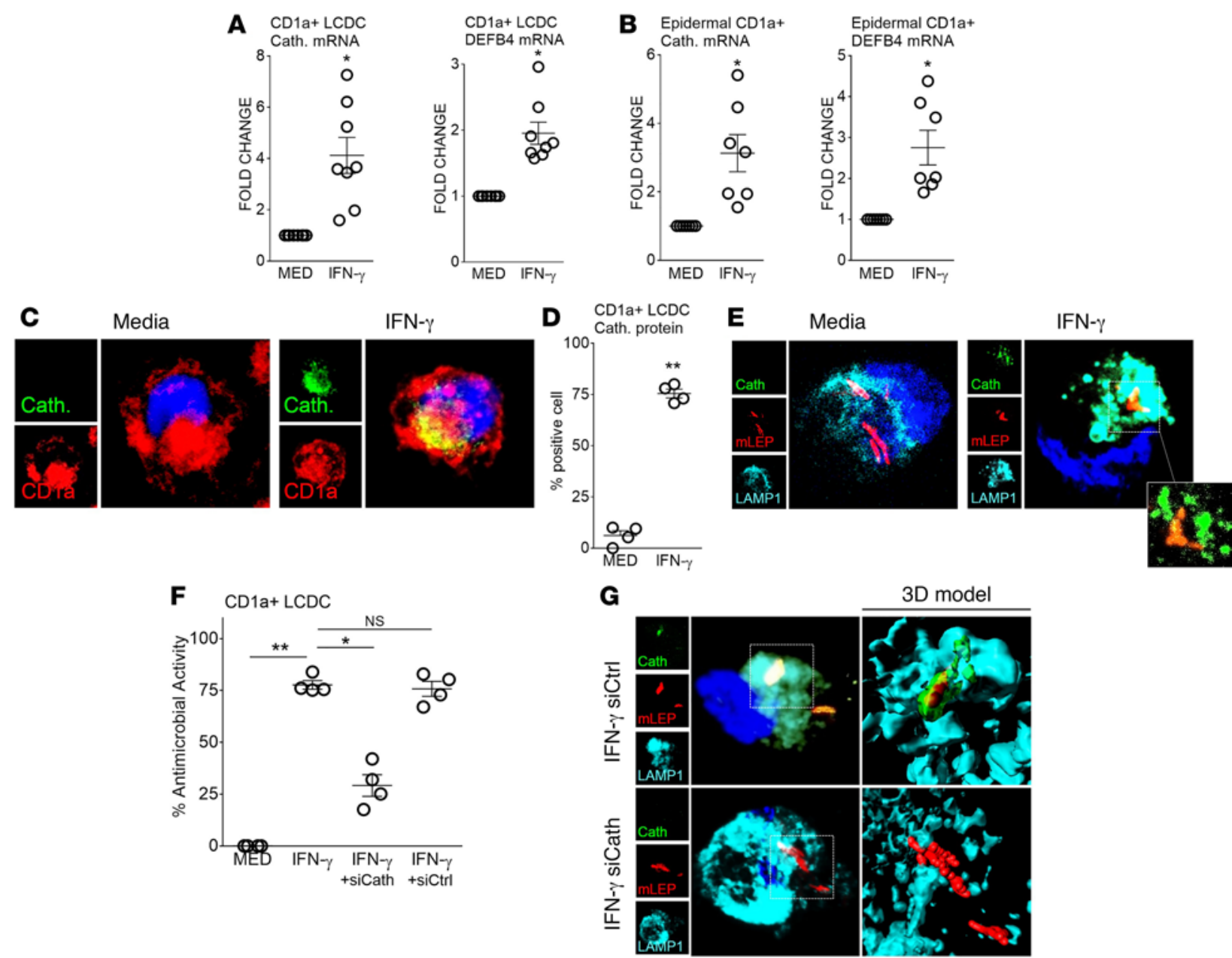

Figure 3. Cathelicidin is involved in antimicrobial activity. Human LCDC were stimulated with rIFN- $\gamma$ in $10 \%$ vitamin D-sufficient human serum. Cathelicidin and DEFB4 gene expression was assessed by qPCR. (A) LCDC data are represented as mean fold change \pm SEM, $n=8$. (B) Human primary CD1a ${ }^{+}$LC data are represented as mean fold change \pm SEM, $n=7$. (C) Human LCDC were stimulated with rIFN- $\gamma$, fixed, and immunolabeled with anti-cathelicidin antibody (green) and anti-CD1a antibody (red). Representative shown of 4 independent experiments. (D) The percentage of cathelici$\mathrm{din}^{+}$cells was determined. Data are represented as mean \pm SEM, $n=4$. (E) Human LCDC were stimulated with rlFN- $\gamma$ for 4 hours, washed and infected with PKH26-M. leprae (red) at a MOI of 10 overnight, and washed and stimulated with rIFN- $\gamma$ for an additional 4 hours. Infected cells were fixed and immunolabeled with anti-cathelicidin antibody (green) and anti-LAMP1 antibody (cyan). Nuclei were stained with DAPI (blue). Overlay of PKH26-M. leprae and cathelicidin, without LAMP1, shown in boxed inset. Representative shown of 4 independent experiments. (F and G) Human LCDC were transfected with siRNA oligos specific for cathelicidin (siCath) or nonspecific (siCTRL) and then treated with rIFN- $\gamma$ in $10 \%$ human vitamin D-sufficient serum for 4 hours, washed and infected with M. leprae overnight, and washed and transfected with siRNA oligos and rIFN- $\gamma$ for an additional 4 days. (F) Viability of $M$. leprae was calculated, and percent increase or decrease relative to no treatment (media) was determined. Data are represented as mean \pm SEM, $n=4$. (G) Following overnight infection with PKH26-M. leprae (red) overnight, LCDC were washed and stimulated with siRNA oligos and rIFN- $\gamma$ for an additional 4 hours and immunolabeled with anti-cathelicidin antibody (green) and anti-LAMP1 antibody (cyan). Representative shown of 3 independent experiments. (C, E, and $\mathbf{G})$ Images captured on a $63 \times$ lens, with $6 \times$ zoom. ${ }^{*} P<0.05$, ${ }^{*} P<0.01$. Two-tailed Student's $t$ test $(\mathbf{A}$, B, and $\mathbf{D})$ or repeated measures 1-way ANOVA (F).

reduced the number of accumulating LC3 puncta, from $19.3 \pm 2.9$ puncta to $5.3 \pm 1.0$ puncta $(P<0.01$; Figure $6 \mathrm{~B})$. Similarly, the percentage of $\mathrm{LC}^{+}$cells was also reduced in the presence of wortmannin (Supplemental Figure 16). The IFN- $\gamma$-induced antimicrobial activity in $M$. leprae-infected LCDC was dramatically inhibited by approximately $75 \%$ by the addition of wortmannin (Figure $6 \mathrm{C}$ ), and by about $50 \%$ by the knockdown of ATG5 (Figure 6D), indicating that induction of autophagy is required for optimal antimicrobial activity.

LC, by their proximity to the external environment, deal with microbial pathogens as they invade via the skin. LC express C-type lectins and other endocytic receptors that mediate the phagocytosis of various microbes $(2,3)$ subsequently instruct the adaptive $\mathrm{T}$ cell response (5-7). There is evidence that LC mediate an antiviral response (40, 41); however, little is known about the ability of LC, or DC in general, to kill such bacteria and fungi as part of the innate immune response. Given that Staphylococcus aureus, Streptococcus pyogenes, 
A Tuberculoid
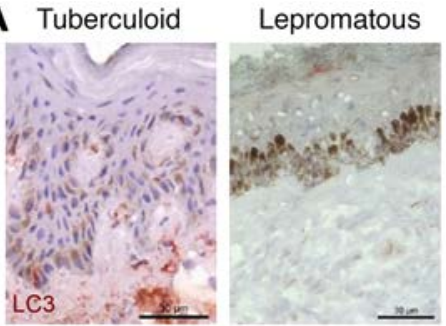

$\mathbf{B}$

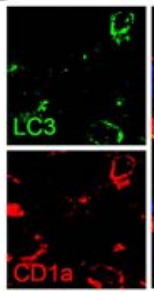

Tuberculoid
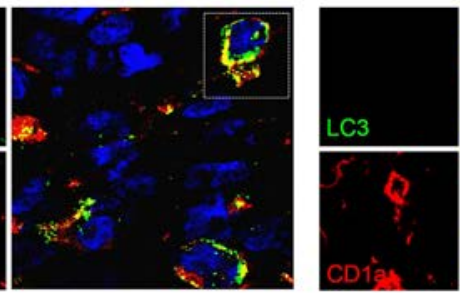

Lepromatous
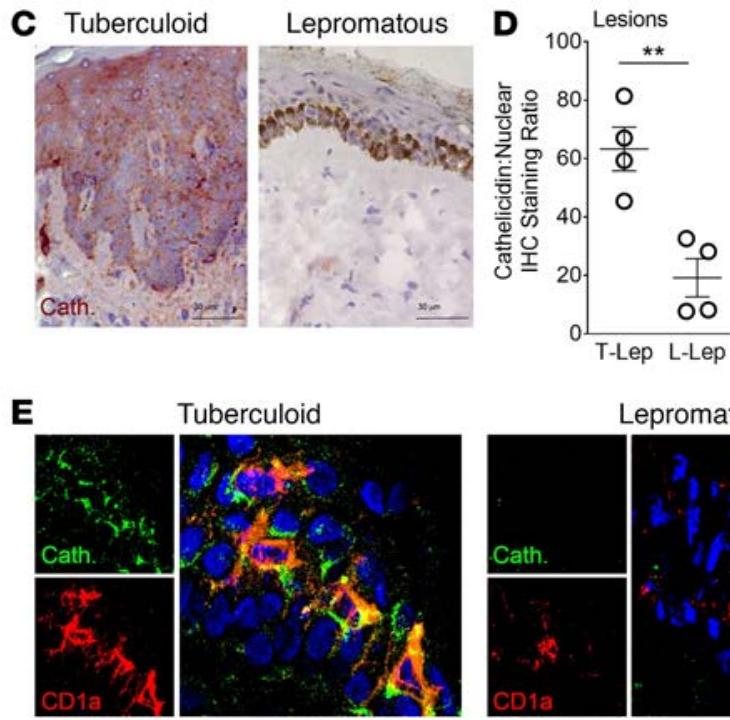

Tuberculoid
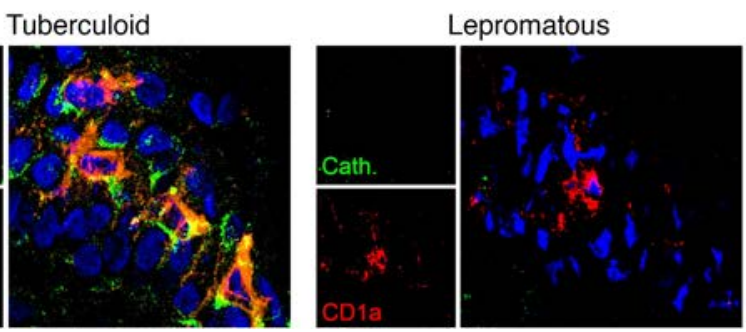

Figure 4. Langerhans cells in leprosy lesions. (A) LC3 expression in leprosy lesions (T-lep and L-lep); 1 representative labeled section is shown out of at 3 individuals at 20x. Scale bar: $30 \mu \mathrm{m}$. (B) Colocalization of LC3 (green) and CD1a (red) in T-lep lesions at 63x. Three-dimensional modeling of corresponding cells in white boxes. Data are representative of 3 individual T-lep or L-Lep samples. (C) Cathelicidin expression in leprosy lesions (T-lep and L-lep); 1 representative labeled section is shown out of at 4 individuals at 20x. Scale bar: $30 \mu \mathrm{m}$. (D) Ratio of cathelicidin and nuclear staining quantified by ImmunoRatio. Data are represented as mean \pm SEM, $n=4$ IHC sections. (E) Colocalization of cathelicidin (green) and CD1a (red) in T-lep lesions. Data are representative of 4 individual T-lep or L-Lep samples at $63 x$.

and C. albicans are frequent skin pathogens, we infected LCDC and/or LC with these organisms and determined whether IFN- $\gamma$ induced an antimicrobial response. IFN- $\gamma$ reduced the viability in $S$. aureus-infected primary LC by about $60 \%$ (Figure 6E). Furthermore, we found that the induction of autophagy by IFN- $\gamma$ was crucial in limiting the growth of $S$. aureus, $S$. pyogenes, and $C$. albicans in infected LCDC (Figure 6, F and G).

Because autophagy has been shown to enhance MHC class I- and MHC class II-restricted antigen presentation $(53,54)$, we investigated whether IFN- $\gamma$-induced autophagy in LC, which reduces bacterial viability, would augment CD1a-restricted antigen presentation of live bacilli. We verified that the treatment of LCDC with IFN- $\gamma$ did not have a substantial effect on the expression of CD1a, regardless of the concentration of 25D or 1,25D in the culture (Supplemental Figure 17, A-F). In addition, the expression of CD1a and HLA-DR were not substantially affected by infection of LCDC with $M$. leprae (Supplemental Figure 17, G and $\mathrm{H}$ ). Next, LCDC were infected with live $M$. leprae and cocultured with the CD1a-restricted T cell clone LCD4.G using a suboptimal number of antigen presenting cells in order to measure augmentation. IL-2 was used as a positive control to demonstrate proliferative response by LCD4.G (Supplemental Figure 18). IFN- $\gamma$ stimulation enhanced antigen presentation by primary human epidermal LC and LCDC, resulting in over a 3 -fold increase in $\mathrm{T}$ cell proliferation compared with antigen alone. The inhibition of IFN- $\gamma$-induced autophagy by wortmannin resulted in an approximately $80 \%$ decrease of the $\mathrm{T}$ cell response (Figure 7, $\mathrm{A}$ and $\mathrm{B}$ ). In comparison, monocyte-derived macrophages (MDM), which did not express CD1a (Supplemental Figure 19) and lack a consensus matching MHC class II allele (Supplemental Table 1), did not present live M. leprae to the CD1a-restricted LCD4.G T cells (Figure 7C). These data indicate that autophagy is required for the ability of LC to efficiently present antigen from live $M$. leprae to T cells. Together, these findings indicate that resident $\mathrm{LC}$ in skin are essential in promoting adaptive $\mathrm{T}_{\mathrm{RM}}$ responses during bacterial infection. 
A

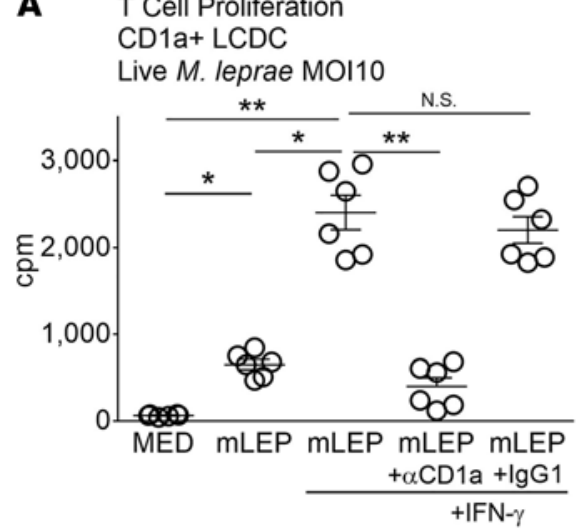

B

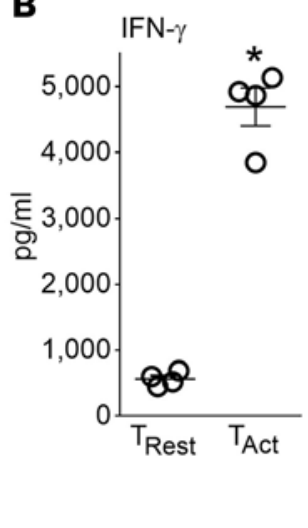

C Cath. mRNA

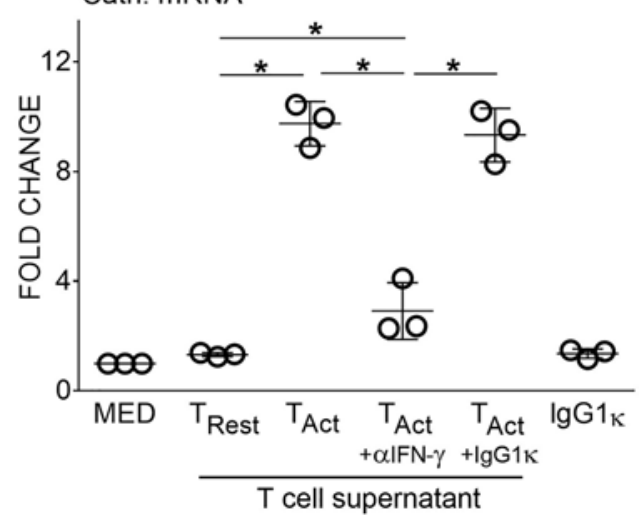

Figure 5. The role of autophagy in Langerhans cells. (A) Human LCDC were stimulated with rIFN- $\gamma$ for 4 hours, washed, and infected with $M$. leprae at a $\mathrm{MOI}$ of 10 overnight; washed and stimulated with rIFN- $\gamma$, with or without blocking anti-CD1a; and cultured with CD4 ${ }^{+}$T cells LCDC4.G, which were isolated from a T-lep lesion. T cells were pulsed with ${ }^{3} \mathrm{H}$-thymidine after 4 days of culture. Cells were harvested, and ${ }^{3} \mathrm{H}$ incorporation was measured by a scintillation counter. Data are represented as mean \pm SEM of triplicate cultures, $n=6$. (B) CD4 ${ }^{+} T_{\text {RM }}$ cells secreted IFN- $\gamma$ upon activation. CD4 ${ }^{+}$T cells (LCD4.G) were stimulated overnight by CD3/CD28 DynaBeads $\left(T_{A c t}\right)$ or cultured in media alone ( $\left.T_{\text {Rest }}\right)$, supernatants were collected, and IFN- $\gamma$ was measured by sandwich ELISA. Data are represented as mean \pm SEM, $n=4$. (C) Human LCDC were cultured with T cell supernatants ( $T_{\text {Rest }}$ and $\left.T_{\text {Act }}\right)$ in the presence or absence of an IFN- $\gamma$ blocking mAb or isotype control antibody in $10 \%$ human vitamin $D$-sufficient serum. Cathelicidin gene expression was assessed by qPCR. Data are represented as mean fold change \pm SEM, $n=3 .{ }^{*} P<0.05,{ }^{* *} P<0.01$. Two-tailed Student's $t$ test or repeated measures 1-way ANOVA.

\section{Discussion}

In primitive eukaryotic organisms such as yeast and amoebas, autophagy has an essential role in cell survival by managing the flow of nutrients and by clearing damaged organelles $(75,76)$. It has become increasingly clear that more complex organisms have evolved to utilize autophagy for other physiologic pathways, including host defense, by bringing phagocytized microbial pathogens to lysosomes where they are destroyed. However, it is not known whether the ability of autophagy to facilitate antigen presentation by DC is linked to an antimicrobial response. Here, we provide evidence that, in LC, which are resident DC at the interface of the skin with the outside environment, autophagy delivers bacterial pathogens to lysosomes, where they are killed and subsequently processed into cognate antigens facilitating $\mathrm{T}$ cell recognition. These data suggest that autophagy is a critical mechanism allowing DC to survive invasion by a microbial pathogen via an antimicrobial response, which contributes to efficient antigen presentation to T cells.

A major function of DC is to bridge the innate and adaptive immune response through the efficient presentation of antigen to T cells. The ability of DC to optimally present antigen via MHC class II is enhanced by the induction of autophagy, as shown in murine models of infection including HSV-1 (77, 78), influenza (79), and mycobacteria $(73,80)$. Induction of autophagy in human DC, albeit derived from monocytes differentiated with GM-CSF and IL-4, enhanced MHC class II presentation of HIV-1 (81) and the C-fragment of tetanus toxin expressed by salmonella (74). Here, we found that IFN- $\gamma$, by inducing autophagy in $M$. leprae-infected LC, enhanced CD1a-restricted antigen presentation of live M. leprae to a CD4 ${ }^{+} \mathrm{T}$ cell line, LCD4.G, derived from the $\mathrm{T}_{\mathrm{RM}}$ population in a leprosy skin lesion. Furthermore, $\mathrm{LC}$ are highly specialized in their function; while IFN- $\gamma$ induced autophagy and antimicrobial activity against mycobacteria in both human LC and macrophages $(34,45)$, only LC were equipped to present $M$. leprae antigen to the CD1a-restricted T cells. LC are not only involved in the presentation of microbial antigens to $\mathrm{T}_{\mathrm{RM}}$, but also present self-antigens to skin-homing T cells via CD1a (19), including skin-derived lipids (13) and free fatty acids (20). Further studies are needed to define the role of autophagy in the different pathways by which LC present antigen to T cells.

Mycobacteria are known to inhibit phagolysosomal fusion (50-55) in macrophages, which is overcome by autophagy $(34,35,56-60)$. In infected human LC, as in macrophages, IFN- $\gamma$ induction of autophagy and subsequent phagolysosomal fusion is required for an antimicrobial activity (34). IFN- $\gamma$ also induces the vitamin D-dependent production of Cath in LC, which is delivered to phagolysosomal compartments containing $M$. leprae and is required for the antimicrobial response. Autophagy components may also contribute to host defense via other pathways (82). There are few studies indicating that DC mount an antimicrobial response against an intracellular pathogen $(40,83)$, with one report indicating that the induction of autophagy enhances antimicrobial function (84). It was recently reported that HIV infection induces auto- 
A

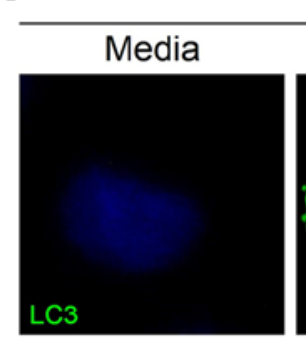

\section{CD1a+ LCDC}
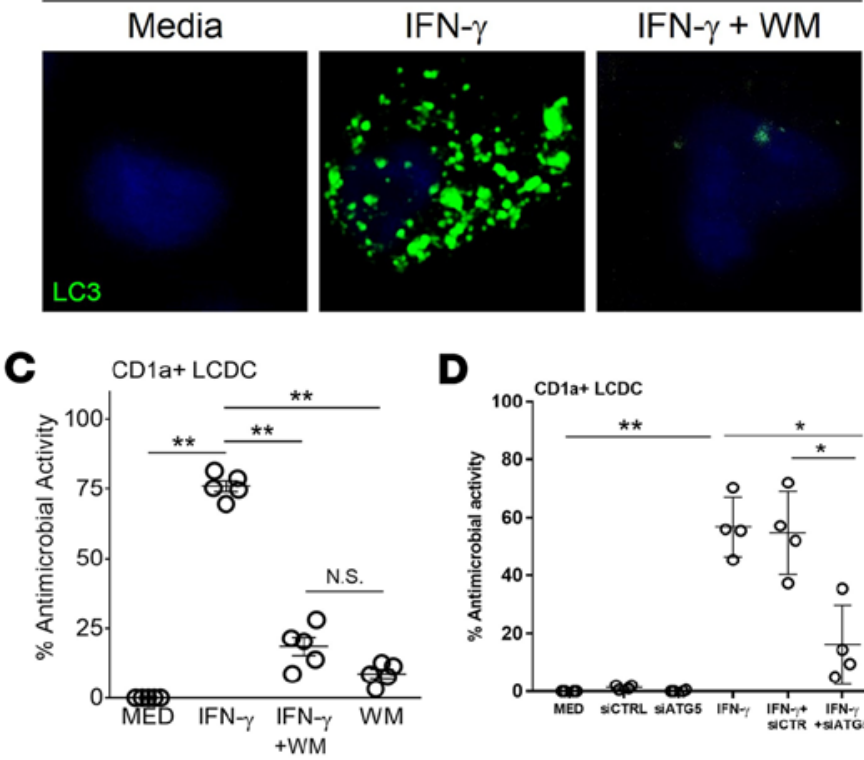

D

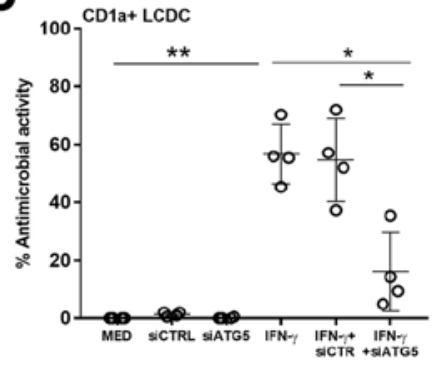

$\mathbf{F}$
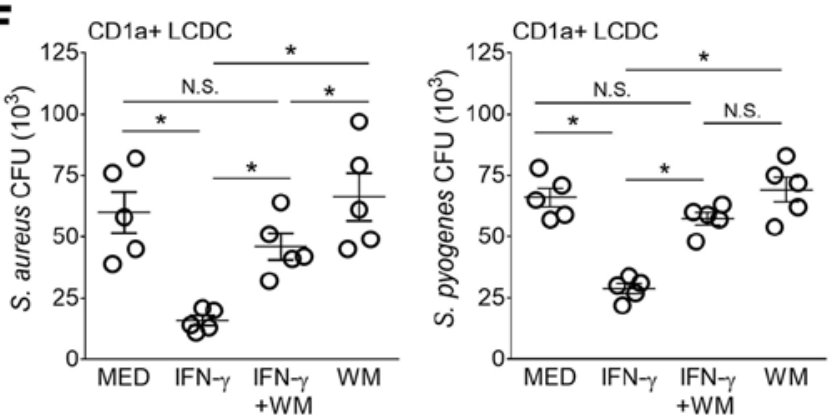

B

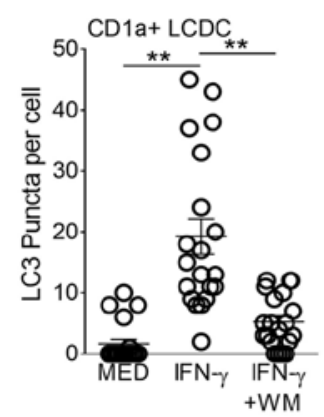

E

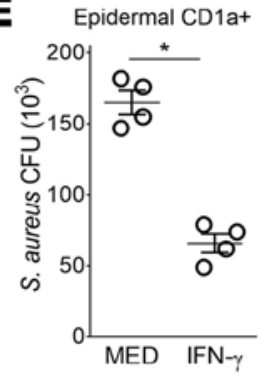

G

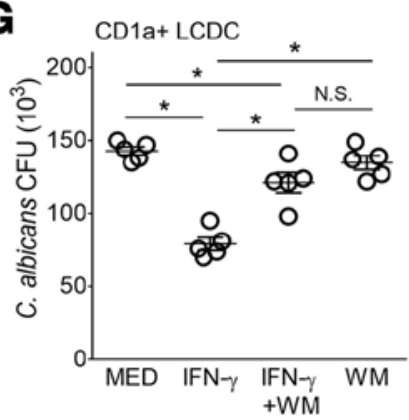

Figure 6. Autophagy is essential for antimicrobial response. (A) LCDC were cultured with rIFN- $\gamma$, with pretreatment of wortmannin (WM) or DMSO (MED) and immunolabeled with anti-LC3 antibody (green). Nuclei were stained with DAPI (blue). Representative shown of 4 independent experiments. Images captured on a $63 \times$ lens, with $6 \times$ zoom. (B) The number of LC3 puncta per cell were quantified. Data are represented as mean puncta per cell \pm SEM, $n \geq 30$ cells. (C) LCDC were stimulated with rIFN- $\gamma$, with pretreatment of WM or DMSO, and infected with $M$. leprae with a MOI of 10 ; they were stimulated with rIFN- $\gamma$, with treatment of WM or DMSO for an additional 4 days. Viability of mLEP was detected by qPCR, and percent increase or decrease relative to media was determined. Data are represented as mean \pm SEM, $n=5$. (D) LCDC were transfected with siRNA oligos for ATG5 (siATC5) or nonspecific (siCtrl) and then treated with rIFN- $\gamma$, followed by $M$. leprae infection overnight, and transfected with siRNAs and rIFN- $\gamma$. Viability of $\mathrm{mLEP}$ was calculated as in C. Data are represented as mean $\pm \mathrm{SEM}, n=4$. (E) Primary CD1a $L C$ were stimulated with rIFN- $\gamma$ and washed and infected with S. aureus at a MOI of 3. Data are represented as mean \pm SEM, $n=4$. (F) LCDC were stimulated with rIFN- $\gamma$, with pretreatment of WM or DMSO for 4 hours, and infected with S. aureus (left) or S. pyogenes (right) at a MOI of 3. Data are represented as mean \pm SEM, $n=5$. (C) LCDC were stimulated with rIFN- $\gamma$, with pretreatment of WM or DMSO, and infected with C. albicans at a MOI of 3 . Viability was quantified by CFU assay for E-G. Data are represented as mean SEM, $n=5$. ${ }^{*} P<0.05,{ }^{* *} P<0.01$. Repeated measures 1-way ANOVA.

phagy in LC, resulting in the trafficking of the virions into the autophagosome for degradation (42). One major limitation of our study is that we are unable to assess the in vivo role of autophagy in the immune response to $M$. leprae, as there is no animal model that mimics the disease spectrum of human leprosy. Also, it is not clear whether vitamin D is required for IFN- $\gamma$-induced autophagy in mouse macrophages and DC. Although IFN- $\gamma$ induction of autophagy is vitamin D dependent, it is not clear if this is true in mouse macrophages. However, our data provide insight into the role of autophagy-induced antimicrobial activity in DC function, suggesting that this host defense pathway also results in the breakdown of the pathogen into cognate antigen for optimal activation of $\mathrm{T}$ cell responses.

We speculate that the ability of DC, such as LC, to mount this antimicrobial response not only contributes to enhanced antigen presentation, but may also represent a multifaceted survival mechanism. We found that IFN- $\gamma$ induced autophagy-dependent antimicrobial activity in LC against other cutaneous pathogens, including $S$. aureus, $S$. pyogenes, and $C$. albicans. Whereas in macrophages, autophagy only contributes to the destruction 

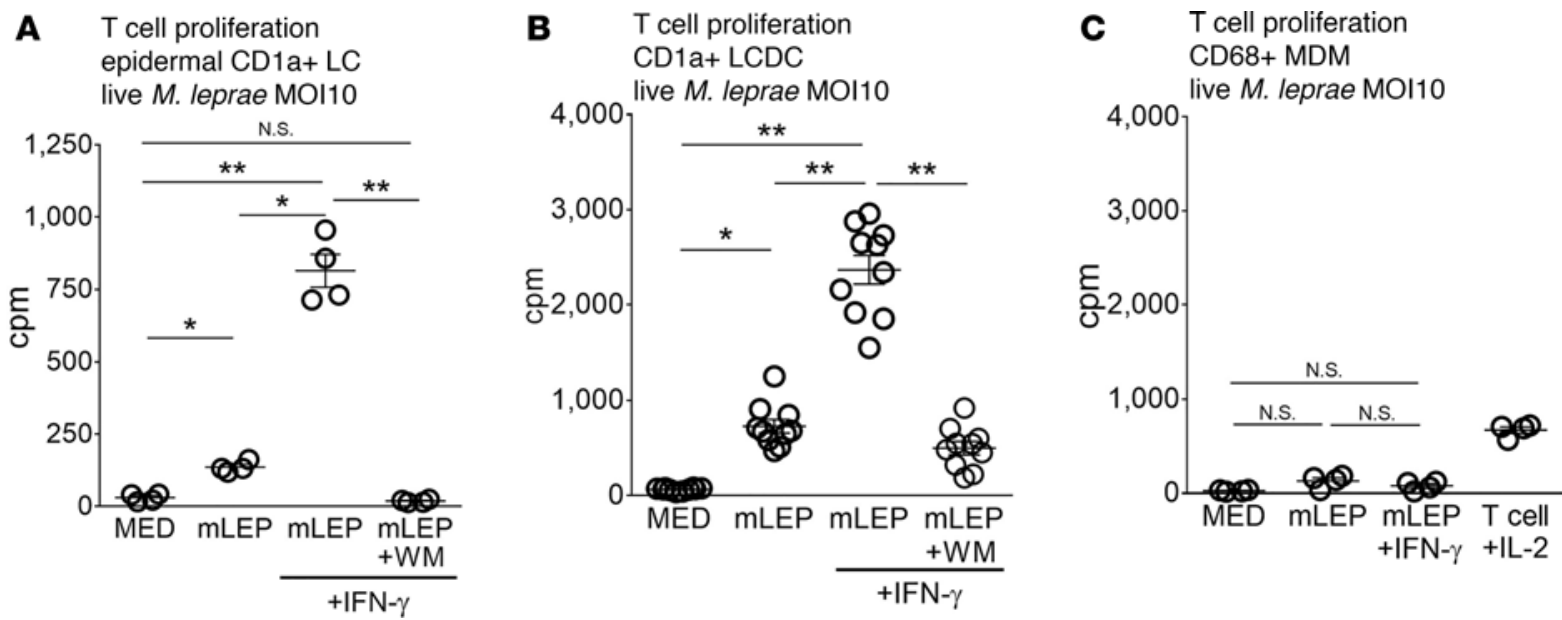

Figure 7. Autophagy contributes to $M$. leprae antigen presentation to $\mathrm{T}$ cells. (A) Human primary CD1a+ $L C$ were stimulated with rIFN- $\gamma$, with pretreatment of wortmannin (WM) or DMSO (MED) for 4 hours; washed and left uninfected (MED) or infected with M. leprae (mLEP) at a MOI of 10 overnight; washed and stimulated with rIFN- $\gamma$, with wortmannin (WM) or DMSO (MED); and cultured with LCDC4.G. T cells were harvested after 4 days, and ${ }^{3} \mathrm{H}$ incorporation was measured by a scintillation counter. Data are represented as mean \pm SEM of triplicate cultures, $n=4$. (B) Human LCDC or (C) monocyte-derived macrophages (MDM) were stimulated, infected, and cultured with LCD4.G T cells as in A. LCD4.G cells were cultured with rlL-2 as positive control. Data are represented as mean \pm SEM of triplicate cultures. LCDC, $n=10 ;$ MDM $n=4 .{ }^{*} P<0.05$, ${ }^{* *} P<0.01$. Repeated measures 1-way ANOVA.

of such microbes (85-88), our data show that autophagy contributes both to an antimicrobial response in LC, which then allows DC to process and present pathogen-derived antigens to T cells, as well as to instruct the nature of the adaptive $\mathrm{T}$ cell response (5-7). The present findings are relevant to host defense at the site of infection, as the LC in leprosy lesions colocalized with IFN- $\gamma$ exhibited an autophagic response and contained Cath protein. Finally, skin-derived LC were able to process and present live $M$. leprae to a $\mathrm{T}_{\mathrm{RM}}$ cell line derived from a leprosy lesion, resulting in the release of IFN- $\gamma$, providing an amplification loop to further augment autophagy, antimicrobial activity, and antigen presentation essential for effective immunity at sites of infection. In summary, these results provide evidence that LC contribute to host defense against cutaneous pathogens.

\section{Methods}

Reagents. Recombinant human IFN- $\gamma$ was purchased from R\&D Systems and used at a concentration of $10 \mathrm{ng} / \mathrm{ml}$. Both 25(OH)D3 and 1,25D3 were purchased from BioMol, dissolved in ethanol, and used at a concentration of $1 \times 10^{-7} \mathrm{M}$. VAZ was obtained from Bayer Schering Pharma AG and used at $1 \times 10^{-9} \mathrm{M}$. Wortmannin, dissolved in DMSO and used at $500 \mathrm{nM}$; rapamycin, dissolved in DMSO and used at 300 nM; poly-L-lysine; and saponin were purchased from MilliporeSigma. RPMI cell culture media, IMDM cell culture media, Hyclone FCS, CD3/CD28 Dynabeads, DAPI antifade with prolong Gold, Lipofectamine RNAiMAX, and TRIzol were purchased from Invitrogen. CD3/CD28 DynaBeads were used at $\mathrm{bead} /$ cell ratio of 1:1. Monoclonal antibodies and their corresponding isotype controls used were the following: anti-IFN- $\gamma$ (clone B27, IgG1 ${ }_{\kappa}$ ), APC anti-human CD1a (clone HI149, IgG1 $1_{\kappa}$, PE anti-human CD80 (clone L307.4, IgG1 ${ }_{\kappa}$ ), PE anti-human CD86 (clone IT2.2, IgG2b ${ }_{k}$ ), and PE anti-human HLADR (clone Tu39, IgG2a $\mathrm{a}_{\mathrm{k}}$ ) were purchased from BD Biosciences. Purified anti-human CD1a (clone SK9, IgG2 $b_{k}$ ), purified anti-human CD207/langerin (clone 4C7, IgG2a), and Alex647 anti-CD107/LAMP1 (clone H4A3, IgG1 $1_{k}$ ) were obtained from BioLegend. PE anti-CD207/langerin (clone DCGM4, IgG1 ${ }_{k}$ ) was purchased from Beckman Coulter. Purified anti-human LC3 (clone 4E12, IgG1 ${ }_{\kappa}$ ) was obtained from MBL International. Anti-Cath (clone OSX12, IgG $1_{k}$ ) and anti- $\beta$-defensin-2 (rabbit polyclonal EPR20469) were purchased from Abcam. CD1a magnetic beads were purchased from Miltenyi Biotec. Recombinant IL-2, used at $1 \mathrm{nM}$, were from Chiron Diagnostics. Recombinant GM-CSF was obtained from Genzyme Corporation, a Sanofi company.

Generation of LCDC. CD34+ cells were cultured in RPMI in the presence of SCF (25 ng/ml), GM-CSF $(100 \mathrm{ng} / \mathrm{ml})$, and TNF- $\alpha(500 \mathrm{ng} / \mathrm{ml})$. At day $9, \mathrm{CD}_{1} 4^{+}$cells were depleted from the culture. The remaining CD14- cells were replated in the presence of GM-CSF $(100 \mathrm{ng} / \mathrm{ml})$ and TGF- $\beta 1(1 \mathrm{ng} / \mathrm{ml})$ to increase CD1a expression. LCDC were harvested at day 13-15 and enriched for CD1a by using anti-CD1a magnetic 
beads. Of the CD1a+ LCDC, $80 \%-90 \%$ were found to also be $\mathrm{CD}^{+} 207^{+}$, by surface staining.

Preparation of human LC. Epidermal cell suspensions were prepared from deidentified normal human skin taken from patients undergoing abdominal plastic surgery at UCLA Division of Plastic and Reconstructive Surgery with the approval of UCLA Tissue Procurement Core Laboratory, as previously described $(6,47)$. The attached adipose and connective tissues were removed, and the skin was cut in approximately into 0.5 $\mathrm{cm}^{2}$ pieces, which were rinse in HBSS (Thermo Fisher Scientific) without calcium, magnesium, or phenol red. Skin pieces were then incubated in $0.2 \%$ dispase HBSS. The epidermis was separated from the dermis, mechanically separated into a single cell suspension, and filtered through $40-\mu \mathrm{m}$ cell strainers (BD Biosciences). $\mathrm{CD} 1 \mathrm{a}^{+} \mathrm{LC}$ were isolated from the epidermal cell suspension by using anti-CD1a magnetic beads. Of the CD $1 \mathrm{a}^{+} \mathrm{LC}, 50 \%$ were found to also be CD $207^{+}$by surface staining. Epidermal LC were cultured in IMDM.

Human serum collection and 25D quantification. Blood was collected from healthy donors in the absence of anticoagulants and allowed to clot for 2 hours. The serum layer was collected and passed through a 0.22 $\mu \mathrm{m}$ filter and frozen in small aliquots at $-80^{\circ} \mathrm{C}$ for future use. The concentration of $25 \mathrm{D}$ was determined by radioimmunoassay, as previously described $(33,89)$. Serum was pooled from several donors to obtain vitamin $\mathrm{D}$-sufficient and vitamin $\mathrm{D}$-insufficient batches. The $25 \mathrm{D}$ level in the vitamin $\mathrm{D}$-sufficient pooled serum batches was approximately $100 \mathrm{nM}(40 \mathrm{ng} / \mathrm{ml})$, and in the vitamin $\mathrm{D}$-insufficient serum, batches less than $35 \mathrm{nM}(14 \mathrm{ng} / \mathrm{ml})$. The 25D level in the FCS was less than $18 \mathrm{nM}$ or $7 \mathrm{ng} / \mathrm{ml}$.

LCDC and epidermal LC culture for PCR. Following CD1a selection, cells were cultured in 10\% FCS or $10 \%$ human serum, with or without $10 \%$ final volume of $\mathrm{T}$ cell supernatants, as indicated. IFN- $\gamma$-induced gene expression of CYP27B1, VDR, CYP24, Cath, and DEFB4 mRNAs were detected after 2 hours.

$P C R$. mRNA was isolated from cells using TRIzol according to the manufacturer-recommended protocol. cDNA was prepared and gene expression levels were measured by quantitative PCR (qPCR) and calculated by the $2^{-(\Delta \mathrm{Ct})}$ method. Primer sequences for human Cath, DEFB4, CYP27B1, VDR, CYP24A1, human 36B4, CD64, and 16S rRNA and M. leprae-specific repetitive element (RLEP) of M. leprae were previously reported $(33,34,48)$.

siRNA transfection of LCDC. Cath siRNA, ATG5 siRNA, and siCTRL, obtained from GE Dharmacon, were incubated with Lipofectamine RNAiMAX (Invitrogen) for 30 minutes to allow complexing. Then, siRNA was added to the LCDC culture at $200 \mathrm{pM}$, per transfection, 30 minutes and overnight prior to the addition of IFN- $\gamma$ for Cath siRNA and ATG5 siRNA, respectively.

Infection of epidermal $L C$ and $L C D C$, treatment with IFN- $\gamma$, and quantification of antimicrobial activity. M. leprae was grown in the footpad of $\mathrm{nu} / \mathrm{nu}$ mice, as described previously (90), and was provided by the National Hansen's Disease Program (Baton Rouge, Louisiana, USA). LCDC were pretreated with $10 \mathrm{ng} / \mathrm{ml}$ of IFN- $\gamma$ or IL-4 in 10\% human serum for 4 hours or overnight. The cells were washed prior to the overnight infection with $M$. leprae at a multiplicity of infection (MOI) of 10 in 10\% FCS. Extracellular bacteria were removed by vigorous washing. The infected cells were then treated again with the same concentration of IFN- $\gamma$ or IL-4 in 10\% human serum and harvested after 4 days. Epidermal LC were treated with IFN- $\gamma$ and infected with mLEP similarly as above. RNA and DNA were isolated from infected cells following TRIzol protocol. The viability of intracellular $M$. leprae was determined by qPCR and quantified as previously described $(45,48,49)$. Briefly, cDNA was synthesized from the total RNA as described for both human and bacterial mRNAs. The $M$. leprae $16 \mathrm{~S}$ rRNA and genomic element DNA (RLEP) levels were then assessed using real-time PCR. In order to normalize for the total number of LC present in culture, 36B4 was also evaluated. Comparison of the bacterial DNA to the mammalian 36B4 levels was used to monitor infectivity between all the conditions in the assay, as well as PCR quality. The 16S rRNA and genomic DNA values were calculated using the $\Delta \Delta \mathrm{CT}$ analysis, with the bacterial DNA value serving as the housekeeping gene. The efficiency of infection was determined by confocal microscopy and FACS. Approximately $45 \%-60 \%$ of cells were infected. Cells viability following washes and infection was $81 \%-87 \%$ of the total cells.

Intracellular killing of S. aureus and S. pyogenes by LCDC and epidermal LC. S. aureus strain DU5938 (Hla ${ }^{-} \mathrm{H1}-$ $\mathrm{b}^{-} \mathrm{Hlg}^{-}$) (91) or $S$. pyogenes (ATCC 700294) (92) were grown to the mid-log phase at $37^{\circ} \mathrm{C}$ with shaking (150 $\mathrm{rpm}$ ) in brain-heart infusion (BHI) medium, collected by centrifugation for 10 minutes at 5,000 $\mathrm{g}$. For cellular infection, the bacterial suspension was diluted with sterile $1 \times$ PBS. The number of viable bacteria was determined by serial dilution and plating onto BHI agar plates (93). LCDC or epidermal LC $\left(5 \times 10^{6}\right.$ cells $)$ were plated in 24-well plate at $1 \mathrm{ml}$ and infected with $S$. aureus at MOI of 3 for 3 hours in $10 \%$ FCS antibiotic-free media. Next, $100 \mu \mathrm{g} / \mathrm{ml}$ of gentamycin was added to the wells for 20 minutes to kill extracellular bacteria. Cells were then washed to further remove any remaining extracellular bacteria. Infected cells were cultured 
overnight in $10 \%$ human serum with or without IFN- $\gamma$ at $37^{\circ} \mathrm{C}$ in a $4 \% \mathrm{CO}_{2}$ incubator (Thermo Scientific Midi 40 Small Capacity CO2 Incubator). To measure intracellular killing of bacteria, cells were pelleted and lysed with $100 \mu 1$ of $0.2 \%$ saponin in $1 \times$ PBS on ice for 20 minutes. PBS $1 \times, 900 \mu 1$, was added to bring the cell lysate to $1 \mathrm{ml}$ final volume, of which $1 \mu \mathrm{l}$ was plated overnight and CFU was determined.

Antifungal activity. Candida albicans (ATCC 18804) were grown by agitation overnight at $28^{\circ} \mathrm{C}$ in yeast mold $(\mathrm{YM})$ media. The cells were then washed twice with $1 \times$ PBS before use as live yeasts $(94)$. LCDC $\left(5 \times 10^{6}\right)$ were plated in 24-well plates at $1 \mathrm{ml}$ and infected with $C$. albicans at MOI of 3 for 3 hours in $10 \%$ FCS antibiotic-free media at $37^{\circ} \mathrm{C}$. Amphotericin B $(1 \mu \mathrm{g} / \mathrm{ml})$ was added to wells for 20 minutes to kill extracellular C. albicans. Cells were then washed to further remove any remaining extracellular $C$. albicans. Infected cells were cultured overnight in $10 \%$ human serum with or without IFN- $\gamma$ at $37^{\circ} \mathrm{C}$ in a $4 \% \mathrm{CO}_{2}$ incubator (Thermo Scientific Midi 40 Small Capacity CO2 Incubator). To measure antifungal activity, cells were pelleted and lysed with $100 \mu 1$ of $0.2 \%$ saponin in $1 \times$ PBS on ice for 20 minutes. PBS $1 \times, 900 \mu 1$, was added to bring the cell lysate to $1 \mathrm{ml}$ final volume, of which $1 \mu \mathrm{l}$ was plated for CFU at room temperature. Colonies were counted after 2 days.

Patients and clinical specimens. Patients with leprosy were classified according to the criteria of Ridley and Jopling (95). The designation of T-lep included patients who were classified clinically as borderline tuberculoid (BT), and the designation of L-lep only included patients classified as "LL" (lepromatous leprosy). All T-lep and L-lep skin biopsy specimens were taken at the time of diagnosis, prior to initiating treatment. Specimens were embedded in OCT medium (Ames), snap frozen in liquid nitrogen, and stored at $-80^{\circ} \mathrm{C}$.

Tissue immunoperoxidase labeling. Frozen tissue sections were blocked with normal horse serum before incubation with mAbs for LC3, Cath, and IFN- $\gamma$ for 60 minutes, followed by incubation with biotinylated horse anti-mouse IgG (see Reagents above) for 30 minutes. Slides were counterstained with hematoxylin and mounted in crystal mounting medium (Biomeda) and were visualized using the ABC Elite system (Vector Laboratories). Skin sections were examined using a Leica microscope (Leica). Ratios were calculated by ImmunoRatio online software (Jorma Isola \& Vilppu Tuominen - Institute of Biomedical Technology, University of Tampere, Tampere, Finland) (96), an automated image analysis application that calculates the percent diaminobenzidine-stained (DAB-stained) nuclear area per total area.

Cell culture immunofluorescence labeling. Cells were treated with IFN- $\gamma$ or left untreated in $10 \%$ human serum or $10 \%$ FCS overnight. Then, cells were washed and infected with live M. leprae (mLEP) at a MOI of 10 overnight and further stimulated with IFN- $\gamma$ in $10 \%$ human serum for 3 hours. Following stimulation or infection, cells were adhered to poly-L-lysine-coated slides for 1 hour. Cells were then washed and fixed for 30 minutes with 4\% PFA before being washed again. Next, cells were permeabilized with $0.25 \%$ saponin for 20 minutes, blocked with serum for 30 minutes, and immunolabeled with primary antibodies for LC3, CD1a, CD207, Cath, or DEFB4 for 2 hours. Following washing, cells were stained with secondary antibodies (see Reagents above) for 90 minutes, washed, and mounted with DAPI. For the quantification of autophagy, the number of puncta per cell and the percentages of LC3 punctated cells, as defined the presence of $>5$ puncta per cell, were evaluated using florescence microscopy and quantified by Imaris and Image J (NIH). Approximately 50-100 cells, over 6 different random fields of view, were scored for each condition of each experiment. Rapamycin was used as a positive control for autophagy induction, and wortmannin was used to inhibit autophagy. DMSO used as vehicle control in all media conditions.

Immunofluorescence of cell cultures was examined using a Leica-TCS-SP MP inverted single confocal laser-scanning and a 2-photon laser microscope (Leica) at the Advanced Microscopy/Spectroscopy Laboratory Macro-Scale Imaging Laboratory (California NanoSystems Institute, UCLA). Three-dimensional modeling of microscopy images were generated by Imaris software.

Tissue immunofluorescence labeling. Immunofluorescence was performed by serially incubating cryostat tissue sections with anti-human mAbs of different isotypes for 2 hours and washed 3 times with $1 \times$ PBS, followed by incubation with isotype-specific, fluorochrome-labeled (A488, A568, A647) goat anti-mouse immunoglobulin antibodies (Molecular Probes) for 90 minutes. Controls included staining with isotype-matched antibodies. Nuclei were stained with DAPI. Immunofluorescence of skin sections was examined using a Leica-TCS-SP MP inverted single confocal laser-scanning and a 2-photon laser microscope (Leica) at the Advanced Microscopy/ Spectroscopy Laboratory Macro-Scale Imaging Laboratory (California NanoSystems Institute, UCLA).

Transmission electron microscopy. Human LCDC were fixed with $2 \%$ paraformaldehyde and $2.5 \%$ glutaraldehyde (Electron Microscopy Sciences) in 1× PBS (Gibco), pH 7.35, for 1 hour at room temperature and stored at $4^{\circ} \mathrm{C}$ overnight. The cell pellets were washed with PBS, embedded in $4 \%$ low-melt agarose, cut into small pieces, and post-fixed with $1 \% \mathrm{OsO}_{4}$ in $\mathrm{ddH}_{2} \mathrm{O}$. Following washing with $\mathrm{ddH}_{2} \mathrm{O}$, the cells 
were stained en bloc with $2 \%$ uranyl acetate, washed, dehydrated through a graded series of ethanol, treated with propylene oxide, and embedded in Eponate 12 (Ted Pella Inc.). Silver to gold interference color sections were cut on a TMC ultramicrotome and picked up on formvar-coated copper grids. The sections were stained with Reynolds lead citrate and examined on a JEOL 100CX electron microscope at $60 \mathrm{kV}$. Images were collected on type $4489 \mathrm{EM}$ film, and the negatives were digitized at $1200 \mathrm{dpi}$. Adobe Photoshop was used to quantify the pixel area of cellular compartments. The volume fractions of images were calculated by dividing the sum of the area occupied by of single- or double-membrane autophagic compartments with the area of the cell (64).

Immunoblotting analysis. LCDC, $1 \times 10^{6}$ per condition, were collected in NP-40 lysis buffer $(50 \mathrm{mM}$ Tris [pH 7.4], $50 \mathrm{mM} \mathrm{NaCl}, 5 \mathrm{mM}$ EDTA, $50 \mathrm{mM} \mathrm{NaF}, 1 \mathrm{mM} \mathrm{Na}_{3} \mathrm{VO}_{4}, 1 \%$ Nonidet P40 [NP40],0.02\% NaN3 and $1 \mathrm{mM}$ PMSF) containing complete protease inhibitors (Roche Applied Science). Total protein from cell lysates were quantified using Bradford Assay. Lysates were separated on a 7.5\% nondenaturing gel, followed by immunoblot analysis with anti- $\beta$-actin and anti-LC3 (see Reagents above) and detected by enhanced chemiluminescence (Pierce Biotechnology).

CD1a-restricted $T$ cell clone. An $M$. leprae-reactive CD4+ T cell line (LCD4.G) was derived from a biopsy of a skin lesion from an untreated patient with T-lep as described (24). To obtain supernatants, $1 \times 10^{6}$ $\mathrm{T}$ cells were cultured in $1 \mathrm{ml}$ of media containing $10 \%$ FCS with or without the addition of CD3/CD28 Dynabeads, with a bead/cell ratio of 1:1. Supernatants were collected after 24 hour stimulation and stored at $-80^{\circ} \mathrm{C}$. IFN- $\gamma$ levels of $\mathrm{T}$ cell supernatants were measured by sandwich ELISA.

Antigen presentation and proliferation assay. LCD4.G is a $\mathrm{CD}^{+} \mathrm{T}$ cell line derived from a tuberculoid lesion as described (24). T cells were maintained by serial antigenic stimulation using LCDC in medium supplemented with recombinant IL-2. Antigen presentation by LC was measured using a suboptimal ratio of $0.1 \mathrm{LC}$ to $1.0 \mathrm{~T}$ cell, instead of $1: 1$, in order to measure both inhibition and augmentation of the $\mathrm{T}$ cell response. Epidermal LC and LCDC were pretreated with $10 \mathrm{ng} / \mathrm{ml}$ of IFN- $\gamma$ in $10 \%$ human serum overnight. The cells were washed prior to the overnight infection with $M$. leprae at a MOI of 10 in $10 \%$ FCS. Extracellular bacteria were removed by vigorous washing. The infected cells were then treated again with the same concentration of IFN- $\gamma$ for 2 hours, and they were washed again to remove IFN- $\gamma$ prior to coculture with $\mathrm{T}$ cells. For measurement of $\mathrm{T}$ cell proliferation, $1 \times 10^{4} \mathrm{~T}$ cells were cultured with $1 \times 10^{3}$ uninfected-LCDC (MED) or mLEP-LC (MOI 10) in 10\% human serum. T cells were also cultured with $100 \mathrm{U} / \mathrm{ml}$ of IL-2 as positive control. Following 4 days of culture in 96 -well plates in triplicate at $37^{\circ} \mathrm{C}$ in a $4 \% \mathrm{CO}_{2}$ incubator, cells were pulsed with ${ }^{3} \mathrm{H}$-thymidine $(1 \mu \mathrm{Ci} /$ well; ICN Biomedicals Inc.) and harvested 4 hours later for liquid scintillation counting. To validate the CD1a restriction of the $\mathrm{T}$ cell lines, neutralizing CD1a monoclonal antibodies $(20 \mu \mathrm{g} / \mathrm{ml})$ were added 30 minutes before the addition of T cells. Alternately, $1 \times 10^{4} \mathrm{~T}$ cells were cultured with $1 \times 10^{3} \mathrm{M}$. leprae-infected monocyte-dervived-macrophage. Following 4 days of culture in 96 -well plates in triplicate at $37^{\circ} \mathrm{C}$ in a $4 \%$ $\mathrm{CO}_{2}$ incubator, cells were pulsed with ${ }^{3} \mathrm{H}$-thymidine $(1 \mu \mathrm{Ci} /$ well; ICN Biomedicals Inc.) and harvested 4 hours later for liquid scintillation counting.

Statistics. Statistics reported are of entire series of experiments and described as mean \pm SEM. GraphPad Prism 6 software was used for graphing and statistical analysis. For comparison between 3 or more groups, we utilized repeated measures 1-way ANOVA, with the Greenhouse-Geisser correction, along with Tukey's multiple comparisons test, with individual variances computed for each comparison. The 2-tailed Student's $t$ test was used for all other 2-group analysis. A $P$ value less than 0.05 was considered significant.

Study approval. This study was conducted according to the principles expressed in the Declaration of Helsinki. The study was approved by UCLA IRB (\#13000047 and \#11001274). All donors provided written informed consent for the collection of peripheral blood and subsequent analysis. All leprosy patients were recruited with approval from the IRB of University of Southern California School of Medicine and the Institutional Ethics Committee of Oswald Cruz Foundation, as well as UCLA.

\section{Author contributions}

RLM and ATD designed the experiments, interpreted the data, and drafted the manuscript. RMBT, PTL, $\mathrm{MG}$, and BRB assisted with the conceptual framework and writing. ATD performed most of the experiments. RMBT, KP, and GC performed the autophagy immunoblotting experiment. RMBT quantified confocal imaging. AC and AL assisted with T cell cultures. ENS and MTO provided the clinical samples. 


\section{Acknowledgments}

We would like to thank M. Cilluffo and the UCLA, Brain Research Institute, Electron Microscopy Core Facility for assistance with the electron microscopy studies; M. Schibler and the UCLA NanoSystems Institute, Advanced Light Microscopy Core Facility for their assistance with the confocal studies; the UCLA Gene and Cell Therapy Core for their procurement of the CD $34^{+}$fetal liver cells through the CFAR grant 5P30 AI028697; and Bayer Pharma AG for the VDR antagonist ZK 159222 (VAZ). The flow cytometry experiments were performed at the UCLA Janis V. Giorgi Flow Cytometry Core Facility. The live M. leprae was provided by the US National Hansen's Disease Programs through financial support from NIAID AAI15006-004. The normal human skin was provided by A. Da Lio and V. Alvarez and the UCLA Division of Plastic \& Reconstructive Surgery. This work was supported in parts by grants from the NIH and the 2015 UCLA Dissertation Year Fellowship.

Address correspondence to: Robert L. Modlin, UCLA Dermatology 52-121 CHS, 10833 Le Conte Avenue, Los Angeles, California 90095, USA. Phone: 310.825.6214; Email: rmodlin@mednet.ucla.edu.

1. Fithian E, Kung P, Goldstein G, Rubenfeld M, Fenoglio C, Edelson R. Reactivity of Langerhans cells with hybridoma antibody. Proc Natl Acad Sci USA. 1981;78(4):2541-2544.

2. Valladeau J, et al. Langerin, a novel C-type lectin specific to Langerhans cells, is an endocytic receptor that induces the formation of Birbeck granules. Immunity. 2000;12(1):71-81.

3. Yang K, et al. Host Langerin (CD207) is a receptor for Yersinia pestis phagocytosis and promotes dissemination. Immunol Cell Biol. 2015;93(9):815-824.

4. Igyártó BZ, Kaplan DH. Antigen presentation by Langerhans cells. Curr Opin Immunol. 2013;25(1):115-119.

5. Igyártó BZ, et al. Skin-resident murine dendritic cell subsets promote distinct and opposing antigen-specific $\mathrm{T}$ helper cell responses. Immunity. 2011;35(2):260-272.

6. Seneschal J, Clark RA, Gehad A, Baecher-Allan CM, Kupper TS. Human epidermal Langerhans cells maintain immune homeostasis in skin by activating skin resident regulatory T cells. Immunity. 2012;36(5):873-884.

7. Kashem SW, et al. Candida albicans morphology and dendritic cell subsets determine T helper cell differentiation. Immunity. 2015;42(2):356-366.

8. Calabi F, Bradbury A. The CD1 system. Tissue Antigens. 1991;37(1):1-9.

9. Sieling PA, et al. CD1 expression by dendritic cells in human leprosy lesions: correlation with effective host immunity. J Immunol. 1999;162(3):1851-1858.

10. Ochoa MT, Loncaric A, Krutzik SR, Becker TC, Modlin RL. "Dermal dendritic cells" comprise two distinct populations: CD1+ dendritic cells and CD209+ macrophages. J Invest Dermatol. 2008;128(9):2225-2231.

11. Harman AN, et al. Identification of lineage relationships and novel markers of blood and skin human dendritic cells. J Immunol. 2013;190(1):66-79.

12. Porcelli S, Brenner MB, Greenstein JL, Balk SP, Terhorst C, Bleicher PA. Recognition of cluster of differentiation 1 antigens by human CD4-CD8-cytolytic T lymphocytes. Nature. 1989;341(6241):447-450.

13. de Jong A, et al. CD1a-autoreactive $\mathrm{T}$ cells recognize natural skin oils that function as headless antigens. Nat Immunol. 2014;15(2):177-185.

14. Shamshiev A, Gober HJ, Donda A, Mazorra Z, Mori L, De Libero G. Presentation of the same glycolipid by different CD1 molecules. J Exp Med. 2002;195(8):1013-1021.

15. Agea E, et al. Human CD1-restricted T cell recognition of lipids from pollens. J Exp Med. 2005;202(2):295-308.

16. Moody DB, et al. T cell activation by lipopeptide antigens. Science. 2004;303(5657):527-531.

17. Zajonc DM, Elsliger MA, Teyton L, Wilson IA. Crystal structure of CD1a in complex with a sulfatide self antigen at a resolution of 2.15 A. Nat Immunol. 2003;4(8):808-815.

18. Zajonc DM, et al. Molecular mechanism of lipopeptide presentation by CD1a. Immunity. 2005;22(2):209-219.

19. de Jong A, Peña-Cruz V, Cheng TY, Clark RA, Van Rhijn I, Moody DB. CD1a-autoreactive T cells are a normal component of the human $\alpha \beta$ T cell repertoire. Nat Immunol. 2010;11(12):1102-1109.

20. Bourgeois EA, et al. Bee venom processes human skin lipids for presentation by CD1a. J Exp Med. 2015;212(2):149-163.

21. Birkinshaw RW, et al. $\alpha \beta$ T cell antigen receptor recognition of CD1a presenting self lipid ligands. Nat Immunol. 2015;16(3):258-266.

22. Modlin RL, Hofman FM, Taylor CR, Rea TH. T lymphocyte subsets in the skin lesions of patients with leprosy. J Am Acad Dermatol. 1983;8(2):182-189.

23. Rea TH, Shen JY, Modlin RL. Epidermal keratinocyte Ia expression, Langerhans cell hyperplasia and lymphocytic infiltration in skin lesions of leprosy. Clin Exp Immunol. 1986;65(2):253-259.

24. Hunger RE, et al. Langerhans cells utilize CD1a and langerin to efficiently present nonpeptide antigens to T cells. J Clin Invest. 2004;113(5):701-708.

25. Ridley DS. The pathogenesis of the early skin lesion in leprosy. J Pathol. 1973;111(3):191-206.

26. Poulter LW, Collings LA, Tung KS, Waters MF. Parasitism of antigen presenting cells in hyperbacillary leprosy. Clin Exp Immunol. 1984;55(3):611-617.

27. Sieling PA, et al. CD1-restricted T cell recognition of microbial lipoglycan antigens. Science. 1995;269(5221):227-230.

28. Stenger S, et al. Differential effects of cytolytic T cell subsets on intracellular infection. Science. 1997;276(5319):1684-1687.

29. Stenger S, et al. An antimicrobial activity of cytolytic T cells mediated by granulysin. Science. 1998;282(5386):121-125.

30. Bruns $\mathrm{H}$, et al. Anti-TNF immunotherapy reduces $\mathrm{CD} 8+\mathrm{T}$ cell-mediated antimicrobial activity against Mycobacterium tuber- 
culosis in humans. J Clin Invest. 2009;119(5):1167-1177.

31. Beckman EM, Porcelli SA, Morita CT, Behar SM, Furlong ST, Brenner MB. Recognition of a lipid antigen by CD1-restricted alpha beta+ T cells. Nature. 1994;372(6507):691-694.

32. Ochoa MT, et al. T-cell release of granulysin contributes to host defense in leprosy. Nat Med. 2001;7(2):174-179.

33. Liu PT, et al. Toll-like receptor triggering of a vitamin D-mediated human antimicrobial response. Science. 2006;311(5768):1770-1773.

34. Fabri M, et al. Vitamin D is required for IFN-gamma-mediated antimicrobial activity of human macrophages. Sci Transl Med. 2011;3(104):104ra102.

35. Rovetta AI, et al. IFNG-mediated immune responses enhance autophagy against Mycobacterium tuberculosis antigens in patients with active tuberculosis. Autophagy. 2014;10(12):2109-2121.

36. Deretic V, Saitoh T, Akira S. Autophagy in infection, inflammation and immunity. Nat Rev Immunol. 2013;13(10):722-737.

37. Huang J, Brumell JH. Bacteria-autophagy interplay: a battle for survival. Nat Rev Microbiol. 2014;12(2):101-114

38. Rekha RS, et al. Phenylbutyrate induces LL-37-dependent autophagy and intracellular killing of Mycobacterium tuberculosis in human macrophages. Autophagy. 2015;11(9):1688-1699.

39. Montoya D, et al. Divergence of macrophage phagocytic and antimicrobial programs in leprosy. Cell Host Microbe. $2009 ; 6(4): 343-353$.

40. de Witte L, et al. Langerin is a natural barrier to HIV-1 transmission by Langerhans cells. Nat Med. 2007;13(3):367-371.

41. Renn CN, et al. TLR activation of Langerhans cell-like dendritic cells triggers an antiviral immune response. J Immunol. 2006;177(1):298-305.

42. Ribeiro CM, et al. Receptor usage dictates HIV-1 restriction by human TRIM5 $\alpha$ in dendritic cell subsets. Nature. 2016;540(7633):448-452.

43. Cooper CL, et al. Analysis of naturally occurring delayed-type hypersensitivity reactions in leprosy by in situ hybridization. J Exp Med. 1989;169(5):1565-1581.

44. Yamamura M, et al. Defining protective responses to pathogens: cytokine profiles in leprosy lesions. Science. 1991;254(5029):277-279.

45. Teles RM, et al. Type I interferon suppresses type II interferon-triggered human anti-mycobacterial responses. Science. 2013;339(6126):1448-1453.

46. Ratzinger G, et al. Mature human Langerhans cells derived from CD34+ hematopoietic progenitors stimulate greater cytolytic $\mathrm{T}$ lymphocyte activity in the absence of bioactive IL-12p70, by either single peptide presentation or cross-priming, than do dermal-interstitial or monocyte-derived dendritic cells. J Immunol. 2004;173(4):2780-2791.

47. Peña-Cruz V, Ito S, Dascher CC, Brenner MB, Sugita M. Epidermal Langerhans cells efficiently mediate CD1a-dependent presentation of microbial lipid antigens to T cells. J Invest Dermatol. 2003;121(3):517-521.

48. Martinez AN, et al. Molecular determination of Mycobacterium leprae viability by use of real-time PCR. J Clin Microbiol. 2009;47(7):2124-2130

49. Liu PT, et al. MicroRNA-21 targets the vitamin D-dependent antimicrobial pathway in leprosy. Nat Med. 2012;18(2):267-273.

50. Armstrong JA, Hart PD. Response of cultured macrophages to Mycobacterium tuberculosis, with observations on fusion of lysosomes with phagosomes. J Exp Med. 1971;134(3 Pt 1):713-740.

51. McDonough KA, Kress Y, Bloom BR. Pathogenesis of tuberculosis: interaction of Mycobacterium tuberculosis with macrophages. Infect Immun. 1993;61(7):2763-2773.

52. Sturgill-Koszycki S, et al. Lack of acidification in Mycobacterium phagosomes produced by exclusion of the vesicular proton-ATPase. Science. 1994;263(5147):678-681.

53. Fratti RA, Chua J, Vergne I, Deretic V. Mycobacterium tuberculosis glycosylated phosphatidylinositol causes phagosome maturation arrest. Proc Natl Acad Sci USA. 2003;100(9):5437-5442.

54. Vergne I, Fratti RA, Hill PJ, Chua J, Belisle J, Deretic V. Mycobacterium tuberculosis phagosome maturation arrest: mycobacterial phosphatidylinositol analog phosphatidylinositol mannoside stimulates early endosomal fusion. Mol Biol Cell. 2004;15(2):751-760.

55. van der Wel N, et al. M. tuberculosis and M. leprae translocate from the phagolysosome to the cytosol in myeloid cells. Cell. 2007;129(7):1287-1298.

56. Gutierrez MG, Master SS, Singh SB, Taylor GA, Colombo MI, Deretic V. Autophagy is a defense mechanism inhibiting BCG and Mycobacterium tuberculosis survival in infected macrophages. Cell. 2004;119(6):753-766.

57. Singh SB, Davis AS, Taylor GA, Deretic V. Human IRGM induces autophagy to eliminate intracellular mycobacteria. Science. 2006;313(5792):1438-1441.

58. Alonso S, Pethe K, Russell DG, Purdy GE. Lysosomal killing of Mycobacterium mediated by ubiquitin-derived peptides is enhanced by autophagy. Proc Natl Acad Sci USA. 2007;104(14):6031-6036.

59. Tiwari S, Choi HP, Matsuzawa T, Pypaert M, MacMicking JD. Targeting of the GTPase Irgm 1 to the phagosomal membrane via PtdIns(3,4)P(2) and PtdIns(3,4,5)P(3) promotes immunity to mycobacteria. Nat Immunol. 2009;10(8):907-917.

60. Castillo EF, et al. Autophagy protects against active tuberculosis by suppressing bacterial burden and inflammation. Proc Natl Acad Sci USA. 2012;109(46):E3168-E3176.

61. Mizushima N, Yoshimori T. How to interpret LC3 immunoblotting. Autophagy. 2007;3(6):542-545

62. Paglin S, et al. A novel response of cancer cells to radiation involves autophagy and formation of acidic vesicles. Cancer Res. 2001;61(2):439-444.

63. Kanzawa T, Bedwell J, Kondo Y, Kondo S, Germano IM. Inhibition of DNA repair for sensitizing resistant glioma cells to temozolomide. J Neurosurg. 2003;99(6):1047-1052.

64. Ylä-Anttila P, Vihinen H, Jokitalo E, Eskelinen EL. Monitoring autophagy by electron microscopy in Mammalian cells. Meth Enzymol. 2009;452:143-164.

65. Ali RS, Falconer A, Ikram M, Bissett CE, Cerio R, Quinn AG. Expression of the peptide antibiotics human beta defensin-1 and human beta defensin-2 in normal human skin. J Invest Dermatol. 2001;117(1):106-111.

66. Méndez-Samperio P, Miranda E, Trejo A. Expression and secretion of cathelicidin LL-37 in human epithelial cells after infection by Mycobacterium bovis Bacillus Calmette-Guérin. Clin Vaccine Immunol. 2008;15(9):1450-1455. 
67. Jiang X, Clark RA, Liu L, Wagers AJ, Fuhlbrigge RC, Kupper TS. Skin infection generates non-migratory memory CD8+ T(RM) cells providing global skin immunity. Nature. 2012;483(7388):227-231.

68. Clark RA. Resident memory T cells in human health and disease. Sci Transl Med. 2015;7(269):269rv1.

69. Ulrichs T, Moody DB, Grant E, Kaufmann SH, Porcelli SA. T-cell responses to CD1-presented lipid antigens in humans with Mycobacterium tuberculosis infection. Infect Immun. 2003;71(6):3076-3087.

70. Roura-Mir C, et al. CD1a and CD1c activate intrathyroidal T cells during Graves' disease and Hashimoto's thyroiditis. J Immunol. 2005;174(6):3773-3780.

71. Yuk JM, et al. Vitamin D3 induces autophagy in human monocytes/macrophages via cathelicidin. Cell Host Microbe. 2009;6(3):231-243.

72. Shin DM, et al. Mycobacterial lipoprotein activates autophagy via TLR2/1/CD14 and a functional vitamin D receptor signalling. Cell Microbiol. 2010;12(11):1648-1665.

73. Jagannath C, Lindsey DR, Dhandayuthapani S, Xu Y, Hunter RL, Eissa NT. Autophagy enhances the efficacy of BCG vaccine by increasing peptide presentation in mouse dendritic cells. Nat Med. 2009;15(3):267-276.

74. Cooney R, et al. NOD2 stimulation induces autophagy in dendritic cells influencing bacterial handling and antigen presentation. Nat Med. 2010;16(1):90-97.

75. Takeshige K, Baba M, Tsuboi S, Noda T, Ohsumi Y. Autophagy in yeast demonstrated with proteinase-deficient mutants and conditions for its induction. J Cell Biol. 1992;119(2):301-311.

76. Otto GP, Wu MY, Kazgan N, Anderson OR, Kessin RH. Macroautophagy is required for multicellular development of the social amoeba Dictyostelium discoideum. J Biol Chem. 2003;278(20):17636-17645.

77. Lee HK, et al. In vivo requirement for Atg5 in antigen presentation by dendritic cells. Immunity. 2010;32(2):227-239.

78. Jiang Y, Yin X, Stuart PM, Leib DA. Dendritic Cell Autophagy Contributes to Herpes Simplex Virus-Driven Stromal Keratitis and Immunopathology. MBio. 2015;6(6):e01426-e01415.

79. Zang F, et al. Autophagy is involved in regulating the immune response of dendritic cells to influenza A (H1N1) pdm09 infection. Immunology. 2016;148(1):56-69.

80. Khan A, et al. Autophagy enhances the Efficacy of BCG Vaccine. In: Jackson WT, Swanson MS, eds. Autophagy, Infection, and the Immune Response. Hoboken, NJ: John Wiley \& Sons, Inc; 2014:245-265.

81. Blanchet FP, Piguet V. Immunoamphisomes in dendritic cells amplify TLR signaling and enhance exogenous antigen presentation on MHC-II. Autophagy. 2010;6(6):816-818.

82. Kimmey JM, et al. Unique role for ATG5 in neutrophil-mediated immunopathology during M. tuberculosis infection. Nature. 2015;528(7583):565-569.

83. Serbina NV, Salazar-Mather TP, Biron CA, Kuziel WA, Pamer EG. TNF/iNOS-producing dendritic cells mediate innate immune defense against bacterial infection. Immunity. 2003;19(1):59-70.

84. El-Awady AR, et al. Porphyromonas gingivalis evasion of autophagy and intracellular killing by human myeloid dendritic cells involves DC-SIGN-TLR2 crosstalk. PLoS Pathog. 2015;10(2):e1004647.

85. Barnett TC, et al. The globally disseminated M1T1 clone of group A Streptococcus evades autophagy for intracellular replication. Cell Host Microbe. 2013;14(6):675-682.

86. Schnaith A, Kashkar H, Leggio SA, Addicks K, Krönke M, Krut O. Staphylococcus aureus subvert autophagy for induction of caspase-independent host cell death. J Biol Chem. 2007;282(4):2695-2706.

87. Tam JM, et al. Dectin-1-dependent LC3 recruitment to phagosomes enhances fungicidal activity in macrophages. $J$ Infect Dis. 2014;210(11):1844-1854.

88. Kanayama M, Inoue M, Danzaki K, Hammer G, He YW, Shinohara ML. Autophagy enhances NFkB activity in specific tissue macrophages by sequestering A20 to boost antifungal immunity. Nat Commun. 2015;6:5779.

89. Hollis BW, Kamerud JQ, Selvaag SR, Lorenz JD, Napoli JL. Determination of vitamin D status by radioimmunoassay with an 125I-labeled tracer. Clin Chem. 1993;39(3):529-533.

90. Lahiri R, Randhawa B, Krahenbuhl J. Application of a viability-staining method for Mycobacterium leprae derived from the athymic (nu/nu) mouse foot pad. J Med Microbiol. 2005;54(Pt 3):235-242.

91. Nilsson IM, Hartford O, Foster T, Tarkowski A. Alpha-toxin and gamma-toxin jointly promote Staphylococcus aureus virulence in murine septic arthritis. Infect Immun. 1999;67(3):1045-1049.

92. Loof TG, Rohde M, Chhatwal GS, Jung S, Medina E. The contribution of dendritic cells to host defenses against Streptococcus pyogenes. J Infect Dis. 2007;196(12):1794-1803.

93. Schindler D, et al. Dendritic cells are central coordinators of the host immune response to Staphylococcus aureus bloodstream infection. Am J Pathol. 2012;181(4):1327-1337.

94. Romagnoli G, et al. The interaction of human dendritic cells with yeast and germ-tube forms of Candida albicans leads to efficient fungal processing, dendritic cell maturation, and acquisition of a Th1 response-promoting function. J Leukoc Biol. 2004;75(1):117-126.

95. Ridley DS, Jopling WH. Classification of leprosy according to immunity. A five-group system. Int J Lepr Other Mycobact Dis. 1966;34(3):255-273.

96. Tuominen VJ, Ruotoistenmäki S, Viitanen A, Jumppanen M, Isola J. ImmunoRatio: a publicly available web application for quantitative image analysis of estrogen receptor (ER), progesterone receptor (PR), and Ki-67. Breast Cancer Res. 2010;12(4):R56. 